Illinois State University

ISU ReD: Research and eData

Theses and Dissertations

4-16-2019

\title{
Understanding Community: Microwear Analysis of Blades at the Mound House Site
}

Silas Levi Chapman

Illinois State University, silaslchapman@comcast.net

Follow this and additional works at: https://ir.library.illinoisstate.edu/etd

Part of the History of Art, Architecture, and Archaeology Commons

\section{Recommended Citation}

Chapman, Silas Levi, "Understanding Community: Microwear Analysis of Blades at the Mound House Site" (2019). Theses and Dissertations. 1118.

https://ir.library.illinoisstate.edu/etd/1118

This Thesis is brought to you for free and open access by ISU ReD: Research and eData. It has been accepted for inclusion in Theses and Dissertations by an authorized administrator of ISU ReD: Research and eData. For more information, please contact ISUReD@ilstu.edu. 


\section{UNDERSTANDING COMMUNITY: MICROWEAR ANALYSIS OF BLADES AT THE MOUND HOUSE SITE}

\section{SILAS LEVI CHAPMAN}

\section{Pages}

Understanding Middle Woodland period sites has been of considerable interest for North American archaeologists since early on in the discipline. Various Middle Woodland period (50 BCE-400CE) cultures participated in shared ideas and behaviors, such as constructing mounds and earthworks and importing exotic materials to make objects for ceremony and for interring with the dead. These shared behaviors and ideas are termed by archaeologists as "Hopewell". The Mound House site is a floodplain mound group thought to have served as a "ritual aggregation center", a place for the dispersed Middle Woodland communities to congregate at certain times of year to reinforce their shared identity. Mound House is located in the Lower Illinois River valley within the floodplain of the Illinois River, where there is a concentration of Middle Woodland sites and activity. Use-wear analysis is a tool that archaeologists can use to identify the materials stone tools were used to cut, scrape, drill, etc. The application of this technique to blades, a tool style associated with Hopewell, at Mound House can reveal what people were doing at Mound House. This thesis applies this technique to the Mound House site to reveal evidence for communal activities such as feasting, while craft production and daily activities play a lesser role at the site. This supports preexisting ideas about Mound House as a center for Middle Woodland people to gather to form a symbolic community. 
KEYWORDS: Archaeology, North American Archaeology, Middle Woodland, Hopewell, UseWear Analysis 
UNDERSTANDING COMMUNITY: MICROWEAR ANALYSIS OF BLADES AT THE

MOUND HOUSE SITE

SILAS LEVI CHAPMAN

A Thesis Submitted in Partial Fulfillment of the Requirements for the Degree of

MASTER OF SCIENCE

Department of Sociology and Anthropology

ILLINOIS STATE UNIVERSITY

2019 
Copyright 2019 Silas Levi Chapman 
UNDERSTANDING COMMUNITY: MICROWEAR ANALYSIS OF BLADES AT THE

MOUND HOUSE SITE

SILAS LEVI CHAPMAN

COMMITTEE MEMBERS:

Gregory L. Miller, Chair

Jason L. King

Abigail C. Stone 


\section{ACKNOWLEDGMENTS}

I would like to thank Dr. G. Logan Miller for his assistance in instructing me on usewear analysis and identifying wear, as well as his guidance as my thesis advisor and serving as my thesis committee chair. I would like to thank the Center for American Archaeology for loaning me the materials that were the basis for this thesis, and Dr. Jason King who acted as my contact with the CAA. I would also like to thank Dr. Jason King and Dr. Abigail Stone for serving on my thesis committee and providing feedback and guidance. Finally, I would like to thank my family and friends who supported me through the time of writing this thesis.

S.L.C. 


\section{CONTENTS}

Page

ACKNOWLEDGMENTS

$\begin{array}{ll}\text { TABLES } & \text { iii }\end{array}$

FIGURES

INTRODUCTION 1

CHAPTER I: THE MIDDLE WOODLAND PERIOD AND HOPEWELL 5

CHAPTER II: THE MOUND HOUSE SITE, 11-GE-7 22

CHAPTER III: PREVIOUS ANALYSES OF HOPEWELL BLADES 27

CHAPTER IV: A BRIEF HISTORY OF USE-WEAR ANALYSIS AND METHODOLOGY 37

CHAPTER V: RESULTS 44

$\begin{array}{ll}\text { CHAPTER VI: DISCUSIION } & 60\end{array}$

$\begin{array}{ll}\text { CONCLUSION } & 78\end{array}$

$\begin{array}{lr}\text { REFERENCES CITED } & 80\end{array}$ 


\section{TABLES}

Table

Page

1. Used Mound House Blades by Context 46

2. Total Site Use Wear by Material Worked 46

3. Blades with Motions of Use Identified 47

4. Mound Area Use Wear 50

5. Habitation Area Use Wear 50

6. Degree of Completeness for Blades, Unused vs Used 59 


\section{FIGURES}

Figure

Page

1. Regional Midwest map showing the location of Mound House and other Midde Woodland sites discussed in this study

2. Map of the Mound House Site with Units and Labels of Mounds and Areas

3. A Selection of Blades and Blade Fragments from Mound House

4. Photos of use-wear on blades

5. Blades with retouch or modification

6. Bone and Antler Use-Wear Distribution at Mound House 51

7. Dry Hide Use-Wear Distribution at Mound House 52

8. Fresh Hide Use-Wear Distribution at Mound House 53

9. Dry Hide and Fresh Hide Combined Use-Wear Distribution at Mound House 54

10. Meat Use-Wear Distribution at Mound House 55

11. Soft Plant Use-Wear Distribution at Mound House 56

12. Stone Use-Wear Distribution at Mound House $\quad 57$

13. Wood Use-Wear Distribution at Mound House 58

14. A comparison of use-wear distributions in the different Mound House contexts 62

15. A comparison of the Mound House site and the Murphy site use-wear assemblages 66

16. A comparison of the Mound House site and the Smith site use-wear assemblages 67

17. A comparison of the Mound House site and the Paint Creek Lake Site \#5 use-wear assemblages

18. A comparison of the Mound House site and the Ft. Ancient site assemblage the North Fort Gateways 
19. A comparison of the Mound House site and the Ft. Ancient site assemblage in Lots 17 and 18

20. A comparison of the Mound House site and the Ft. Ancient site assemblage in the Twin Mounds area

21. A comparison of the Mound House site and the Ft. Ancient site assemblage in the Interior Household Cluster

22. A comparison of the Mound House site and the Ft. Ancient site assemblage in the Moorehead Circle

23. A comparison of the Mound House site and the Ft. Ancient site assemblage in Waterline Trench Six

24. A comparison of the Mound House site and the Ft. Ancient site assemblage in the Middle Fort area 


\section{INTRODUCTION}

This thesis is a presentation of a microwear analysis of lithic blades from the Mound House site. This mound group is located in the floodplain of the Lower Illinois River Valley and served as gathering space for Middle Woodland communities in the region. We as archaeologists know a lot about the mound construction sequence at the site and that ritual activity took place here. While ceremonies and community formation seem to have been important at Mound House, little is known about additional activities, ceremonial or otherwise, that took place there, other than mound construction. Mound House, like other Middle Woodland floodplain mound groups in this region of Illinois, has been conceptualized as a regional ceremonial centers, where a symbolic community gathered for ceremonial and cooperative activities (King, Buikstra, and Charles 2011; Ruby et al. 2005). The Mound House site in particular has been noted for the unique ritual complexity at the site, evidenced by a pre-mound ritual screen underneath mound 1 .

Blade use during the Middle Woodland period (50 BCE-400 CE) is strongly associated with the rise and spread of Hopewell. Hopewell refers to collections of material culture made from exotic materials that were sourced and exchanged over the North American Midcontinent in connection with specific styles of building mounds and other earthworks. Most Hopewell artifacts were not utilitarian objects and were interred with the dead in burial mounds as grave goods. Blades start appearing with early Hopewell sites and spread where other Hopewell artifacts and ideas had been. When Hopewell disappeared at the end of the Middle Woodland period, so did the use of blades (Fortier 2000; Miller 2018a), suggesting that the invention and use of blades during the Middle Woodland period was a Hopewell practice. Another reason Hopewell blades have captured the attention of archaeologists is that this technology existed alongside flake and bifacial stone tool technology, which would seemingly make it a redundant 
tool form. This has led to speculation of blades being a technological adaptation, perhaps as a tool to fit a specialized niche, such as in the production of Hopewell artifacts (Grubb 1981; Reid 1976). Others have speculated that Hopewell blades were a tool type that largely function to symbolize Hopewell identity (Morrow 1987).

The application of use-wear to Hopewell blades allows archaeologists to truly identify their function. Microwear analysis allows for each individual tool to be identified, and in turn, whole assemblages. Since the early 1990's there have been multiple applications of microwear analysis to Hopewell blades (Kay and Mainfort 2014; Lemons and Church 1998; Miller 2015; 2018; Odell 1994; Yerkes 1994). Considering how long and intensely North American archaeology has been interested in Hopewell and the Middle Woodland, it is surprising that there are not more functional analyses of blades at Illinois sites. Most of these studies have been with Ohio Middle Woodland sites (Lemons and Church 1998; Miller 2015; 2018; Yerkes 1994), one study has examined those from Illinois sites (Odell 1994), and others on Hopewell blades in the Southeast (Kay and Mainfort 2014; Kimball 1992). Odell (1994) used low-power microscopy in his study, which can tell the observer less about the material the tool contact than high-power microscopy techniques. This makes this thesis the only application of high-power microscopy techniques to Illinois Hopewell Blades.

Previous studies of Hopewell blade use-wear have shown that blades were not specialized tools but were used to perform a wide variety of tasks including butchering, hide processing, woodworking, working bone and antler, carving stone and shell, and much more. This analysis of blades at Mound House was aimed at determining the function blades and to see if there was an overall pattern of wear suggesting generalized, specialized, crafting, etc. In addition to the overall site patterns, any differences between the mound area and the "habitation" area with 
structures present were examined. Overall, the pattern revealed by the analysis shows that Mound House blades were used for a variety of functions, as similar studies have demonstrated at other sites. Blades at Mound House do not appear to be specialized, although the majority of the use-wear relates to meat-cutting wear, which potentially reflects feasting activity. Activities that relate to the production of Hopewell craft items are only evidenced by the use-wear in small proportions, The goal of this use-wear analysis is to better understand the types of activities the people who used Mound House undertook during their time there. A key part of the value of this study is the use of high-power microscopy, which has not been done in the Illinois region for analyzing Hopewell blades. This will allow us to better understand Middle Woodland people in Illinois. This thesis also expands upon the understanding of Hopewell by adding accumulated knowledge from similar microwear studies, thereby expanding the knowledge of how blades functioned in a variety of site contexts and regions. Having a large set of use-wear data covering a number of different sites across many regions allows archaeologists to better understand Hopewell and Middle Woodland activities on a broad scale. It also allows archaeologists to note when the kinds of activities evidenced by use-wear from an assemblage are unique, since they would have comparable sites to compare them to. This thesis aims to examine the blade assemblage to see if the microwear data fits the expected function of the Mound House site as a symbolic community center and shed light on the activities that occurred here.

Chapter 1 of this thesis is a review of the literature on the Middle Woodland period and Hopewell to give cultural context to this study. Chapter 2 of this thesis is a review of the research on Mound House and the current understanding of the site. Chapter 3 of this study is a review of literature of similar studies of Hopewell blade microwear analyses. Chapter 4 provides a definition of use-wear analysis as well as a short history of the method and presents the methods 
employed in this thesis. Chapter 5 provides the results of the microwear analysis of the blades. Chapter 6 is a discussion of the results and contextualizes them in what is known about the Mound House site and compares the data to other studies of Hopewell blade use-wear. 


\section{CHAPTER I: THE MIDDLE WOODLAND PERIOD AND HOPEWELL}

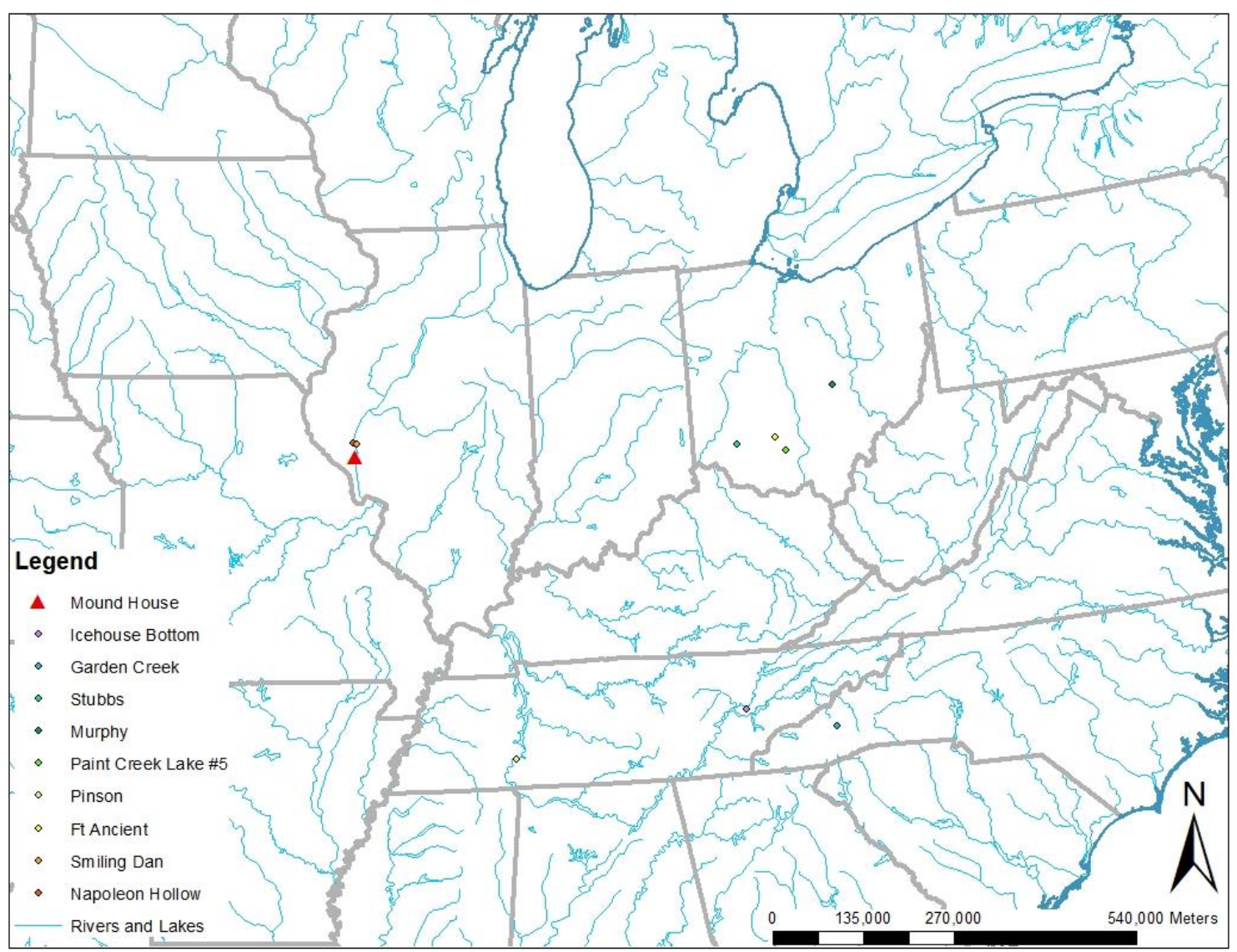

Figure 1. Regional Midwest map showing the location of Mound House and other Midde Woodland sites discussed in this study.

Within this study, two particular descriptors are used when talking about the people and their material record under examination: Middle Woodland and Hopewell. The Middle Woodland period is a subdivision of the Woodland Period, which is a segment of time archaeologists have termed because of certain developments and technologies in North America's Eastern Woodlands. In the Lower Illinois River Valley, the Middle Woodland period begins around $50 \mathrm{cal}$. BCE and ends around $400 \mathrm{cal}$. CE. Archaeologists characterize the Middle Woodland by the widespread use of pottery and intensification of horticulture (Charles et. al 
2004; Dancey 2005). The Middle Woodland period is made distinct by the styles of ceramic, lithic technologies, and mortuary treatments during a period of $50 \mathrm{BCE}-400 \mathrm{CE}$, although this date varies regionally. Hopewell is roughly contemporaneous with the Middle Woodland period. Hopewell is the name given to the type Hopewell site in Ohio by Warren K. Moorehead after the name of the property power (Dancey 2005). Historically, archaeologists used Hopewell to describe a homogenous group in its various regional expressions (Abrams 2009; Dancey 2005). Currently it is a term used by archaeologists to describe specific artifact styles (often grave goods) made from exotic materials, and specific mortuary ceremonial patterns as evidenced by earthwork styles and constructions. Hopewell materials are often distinct and recognizable wherever they are found. Hopewell artifacts and earthworks have a northern boundary in the southern parts of modern-day Michigan and Wisconsin. Hopewell extends south to Mississippi, Alabama, and the panhandle of Florida. The Western boundary only slightly extends west of the Mississippi River, while the eastern boundary is a north-south line that roughly extends down from the eastern border of Ohio (Charleset al. 2004; Struever and Houart 1972). Since Hopewell refers to specific artifacts, earthworks, and their associated behaviors and ideas, while Middle Woodland refers to a time period, the terms "Hopewell" and "Middle Woodland" should not be used interchangeably.

In order to properly understand current academic ideas of Hopewell and Middle Woodland, it is important to provide a brief history of Hopewell archaeology. Interpretations have varied wildly over the years since European settlers encountered mounds. In the $19^{\text {th }}$ century, people believed that a race of Mound Builders were responsible for the mounds they saw, a race that existed until it was wiped out by the Native Americans the Europeans encountered (Charles et al. 2004). In the decades following Warren K. Moorehead's excavation 
of the Hopewell site, the Hopewell culture concept developed (Dancey 2005). This was the dominant idea up through the mid-20 $0^{\text {th }}$ century. Since excavations focused exclusively on mound and earthwork sites, Hopewell was largely characterized by the exotic grave goods and burial practices that were encountered (Charles et al. 2004; Struever and Houart 1972). The Hopewell culture was characterized as a single unitary culture that stretched from as far east as New York, west to Kansas, as far north as Michigan, all the way to the Gulf Coast (Struever and Houart 1972). It was also during this period that Hopewell was attributed to the Middle Woodland period. With the rise of New Archaeology, a new prominent theory concerning Hopewell developed, the Hopewell Interaction Sphere (HIS) model. A formalization of current ideas at the time, "Interaction Spheres in Prehistory", a 1964 work by Joseph R. Caldwell, attempted to explain Hopewell in terms of new archaeological evidence and current trends in anthropological theory (Caldwell 1964; Struever and Houart 1972). Caldwell recognizes that Hopewell burial goods and mortuary activities do not define a whole culture and that the archaeological record shows regional variation across the "Hopewell" cultures. This variation was also reflected in the domestic sites and other non-mortuary Middle Woodland sites being researched. Caldwell saw Hopewell as a set of religious and political ideas expressed through material manifestations, which overlaid the other components of various regional cultures (Caldwell 1964; Charles et al. 2004). The interaction sphere refers to the various regional traditions interacting within and beyond their regional boundaries. Caldwell (1964) does not delve deep into what forces promoted this interaction, or the specifics of the religious or political forces that drove them. Caldwell does attribute the religion of Hopewell as being focused on mortuary ritual.

The Interaction Sphere model has been adapted by other scholars since Caldwell's (1964) work. Struever and Houart's 1972 work "An Analysis of the Hopewell Interaction Sphere" 
brings more complexity to the HIS, as well as mechanisms that drove it, and emphasizes a more economic role for the HIS. The authors do maintain that there is a difference between Middle Woodland cultures and cultural traditions and the Hopewell Interaction Sphere that they participated in. The Hopewell Interaction Sphere serves as a system of trade networks which Middle Woodland people participated in. They introduce the idea of "regional transaction centers", large sites with a large amount of Interaction Sphere goods that sat on major river complexes (Struever and Houart 1972). These regional transaction centers served to maintain transactional ties within a specific area, controlling the flow of Interaction Sphere items. Struever and Houart (1972) did not see the HIS as a homogenous unit, but as a system of interaction networks of various types and scales. These regional transaction centers functioned with local transaction centers to form an interlocal interaction network. Materials from the regional transaction centers moved were exchanged with local transaction centers out to individual sites within the network. Regional transaction centers funneled materials from their sources and exchanged them with each other. Struever and Houart (1972) also proposed interregional exchange networks, which exchanged exotic materials over an ever-larger area. They proposed that these different kinds and levels of networks exchanged different kinds of artifact styles and materials. The Hopewell Interaction Sphere model is still prominent in current literature. Sarich (2010) attempts to find the common theme in various models of the HIS through comparison. Through comparison of several different explanations by various authors on the driving force of Hopewell exchange, Sarich sees an emphasis on ceremony and ritual. This is unsurprising as Hopewellian items tend not to be utilitarian and are often interpreted as ritual in nature. As such, scholars emphasize the role the ritual ideas attached to these items had in facilitating exchange between Middle Woodland peoples. 
Not all researchers are satisfied with the Hopewell Interaction Sphere Model. Charles and others (2004) work, "From the Earth, Minerals and Meaning in the Hopewellian World" explores an alternative interpretation of Hopewell. These researchers think that Hopewell represents a manifestation of economic, social, and political activity during the Middle Woodland period, and is not a shared religion or a formally organized trade network (Charles et al. 2004). This thesis will understand Hopewell and the Middle Woodland period in the framework these authors set up. They approach understanding Hopewell through using historically recorded Native American beliefs and stories to understand why Middle Woodland people created Hopewell objects and mounds. Since Hopewell mounds have a complex internal structure (Buikstra et al. 1998; Charles et al. 2004), they seek to understand what this may have represented to the people who made them. Two cosmological ideas have been hypothesized to relate to mound construction. The first idea is of a "tri-realm" view of reality. This worldview is widespread across many Native American groups, and even has been traced to groups in northeastern Siberia, the region where Native American ancestors are thought to have come from (Charles et al. 2004). This view holds that there are three realms of reality, an Under World, located beneath the earth and waters, This World, and above the sky, and Upper World (Charles et al. 2004). The act of stripping down the A horizon may have been an act exposing the Under World, and the placement of soil on top serves to recreate This World (Charles et al. 2004). The second idea presented in this work is that Middle Woodland mound building and symbolism relates to the Earth Diver story of creation, which is part of the Historic/contemporaneous Native American worldview. Again, this is widespread among Native American cultural groups, and variations exist in Old World cultures as well. The general premise is that the world began fully immersed in water. The animals decide to create land upon which to live. There is mud at the bottom of the waters, but it 
is a long way down. After several animals fail, one manages to bring up a small amount, which expands into the land. Depending on the Native American group, which animal succeeds is different. To some a muskrat retrieves the mud; although in groups like the Ojibwe, Ottawas, Foxes, and Onondaga, in Cherokee versions, a water beetle does, and the list of animals vary (Hall 1977). Many of these animals are those that are subaquatic or live in wetland areas. These cosmological ideas may also be represented in Hopewell artifact styles. For example, platform pipes are a diagnostic Hopewell artifact, which may have plain bowls, or that may be shaped in animals. These animals often occupy more than one of the realms (water, earth, sky) such as waterbirds, frogs, beavers, and more (Brown 2006). Charles and others (2004) suggest that the creation of mounds in fact represents the recreation of the world as laid out in these worldviews. The layer of sand at the base of the mound represents the world as this plane of existence, and the ramp that led to the burial crypt represents the physical world, being brought up into existence (Charles et al. 2004). The soils in the mound construction that were not visible in the immediate vicinity may have served to differentiate the mound from the local soil, providing a contrast that may have made it feel more special.

Carr (2004) suggests that extra local materials were representative of places of power, such as prominent landscapes, like cliffs, waterfalls, and bodies of water. Bringing these materials back from these places would serve as proof of knowledge of this power. This idea suggests that at least some Middle Woodland people, perhaps shaman, people seeking spiritual revelation, or as part of coming of age, physically went these places. As these objects were exchanged and spread through the Middle Woodland world, so did the esoteric knowledge pass to the people who bore them (Carr 2004). The physical properties of these objects were important as well. Obsidian, polished copper, and galena are all very reflective. The color of 
these objects may also have been important. Utilitarian objects that Middle Woodland people often (not always) have dull colors. Chert is often dull white, some shade of grey, or brown before heat treatment. Pottery usually is a reddish earthen color. Bones, antler, and plant material also tends to be dull colors as well. Hopewell materials tend to be very distinct compared with the plain colors of utilitarian objects. Obsidian is jet black and shiny. Knife River flint is a dull brown, yet pleasantly glows when backlit. Copper is a distinctive orange that glows in the light. Mica is a greenish brown, but is highly translucent which gives it a unique appearance. Charles and others (2004) argue that these physical properties, which make Hopewell artifacts conspicuous today, would have made them conspicuous to Middle Woodland people aiding in the process of communicating ideas across time and space. However, what makes a material Hopewell is not just determined by originating from extra-locally or by their physical properties alone. Morrow (1991) shows that sometimes local materials of similar colors were substituted for extra-local materials when making Hopewell crafts. Bear canines were replicated with copper, mica, and animal bone, suggesting that their meaning had something deeper than just the physical properties of the teeth (Charles, Van Nest, and Buikstra 2004). As discussed with the pipes, Hopewell artifacts may represent elements or concepts from Middle Woodland worldviews. As such, these objects could be used to communicate these symbolic ideas across time and space. Considering the range of Hopewell influence, there may have been language boundaries or differences in regional cultures that could have been breached by the use of these objects, representing shared ideas about the world. Seeman (1995) argues that the symbolic nature of Hopewell objects served to transcend language barriers and communicate a diversity of messages. These Hopewell objects share stylistic traits over a broad geographic range, which would allow their use to be able to communicate with anyone who recognized them. 
Since Hopewell materials are often found in mortuary contexts or in intentional deposits, it is easy to view them as ritual mortuary objects. Charles and others (2004) warn against this assumption. While these objects certainly were imbued with symbolic meaning reflecting Middle Woodland worldviews, the authors argue that the frequency and intensification of these objects is related to local social, economic, and political activity as Middle Woodland people were moving around the landscape (2004). Mortuary activities do play a role in Middle Woodland beliefs and the role of mounds, but archaeologists should be careful to not exclusively focus on this. Mounds played a role as active structures, rather than just a final resting place for the dead (Charles et al. 2004). For example, mound 1 at Mound House, for instance, shows signs of several rebuilding events or modifications before it reached its final construction (Buikstra et al. 1998). Hopewell objects may also have had significant, even multi-generational use lives before being deposited in mortuary contexts (Charles et al. 2004; Dancey 2005). Hopewell and Middle Woodland should not be viewed as a contrasting "sacred vs. profane" dichotomy. Sacred and ceremonial aspects would have been a part of the lives of Middle Woodland people both while engaging with Hopewell objects and mounds, it would have also been a part of their lives apart from it as well (Charles et al. 2004). Hopewell blades are actually a great example of this. Blades are a diagnostic Hopewell, not Middle Woodland, artifact (Fortier 2000; Kay and Mainfort 2014). Studies have shown that these blades function both in utilitarian tasks and the production of Hopewell craft objects (Miller 2015; Kay and Mainfort 2014; Odell 1994; Yerkes 1994) but did not function exclusively as a profane or sacred tool.

The exchange of Hopewell materials occurred on three different scales within Middle Woodland groups, local, regional, and interregional. These scales can also be thought of exchange between people who interact regularly with each other, close strangers, and foreigners 
(Carr 2005; Helms 1988). However, the mechanisms of exchange that occurred on these scales deserves further description. Exotic materials from distant places may have been retrieved by shamans (Brown 2006; Carr 2005). Before the evidence for shamanism is explored in Middle Woodland contexts, the term should be defined. In his argument for a shaman presence in Hopewell contexts, Brown (2006) defines a shaman as a ritual specialist who uses altered states of consciousness to contact spirits and supernatural beings, heal the sick, control animals, and influence the weather. Shamans, according to Brown, exist for the most part in small-scale societies, such as hunter-gatherers. Brown distinguishes shamans from medicine men and women, who do not necessarily use altered states of consciousness and often treat ill of a more naturalistic cause, while shamans treat disease that is determined to have a supernatural origin. Brown (2006) lays out several aspects of shamanism and evidence in the archaeological record that suggests their presence in Middle Woodland contexts and with Hopewell artifacts. Transformational imagery, that of a human transforming to an animal or vice versa, is a common theme in hunter-gatherer shamanistic imagery. Brown mentions the Wray sculpture, a stone figurine found at the Newark site in Ohio. This shows a man, complete with Hopewellian hairstyle and copper earspools, draped in a bearskin cape with the head of the bear upon the man's head. Another example of transformational imagery is a carved piece of human bone at the Turner site. Smoking pipes are something that leads Brown to think a shamanistic element is present in Middle Woodland Hopewell practices. Due to the ritualized nature of tobacco smoking and usage in historic Native American societies, Brown (2006) finds it doubtful that Hopewell platform pipes served as recreational smoking pipes. The position of the bowl to direct smoke upwards fits with ethnographic accounts of smoke likened to a "message delivered skyward to the divine" (Brown 2006). Platform pipes have the bowl positioned in the center of a horizontal 
platform, with a hole extending outward from the base of the bowl, through the mass of the platform, coming out at the end. This whole has a very narrow diameter, which would not allow for the insertion of a pipe stem other than one of very slender, fragile reed. Likely, the smoker would have placed their lips directly on the end of the platform where the hole exits. This would effectively put the smoker's lips and lungs in closer proximity to the burning tobacco, as Brown notes (2006). Perhaps more significantly, this places the smoker in close proximity to the bowl. While many Hopewell platform pipe's bowl are a round, "monitor" design, animal effigies are also common (Brown 2006; Emerson et al. 2013). For at least some of the pipes, the animal effigy faces the same direction as the stem hole, which would have aided in any sort of hallucinogenic experience by the smoker (Brown 2006). This is significant because of the large role hallucinogenic experiences have in shamanic practices (Brown 2006; von Gernet 2000). The choice of animals may have been important as well. As discussed previously, many of these platform pipes have animals that move between or habit more than one realm, that is, the sky, the earth, and the waters. Birds that utilize water, as well as animals like beavers, otters, frogs, and other swimming animals, are among some of the best represented animal effigies on Hopewell platform pipes (Brown 2006). Brown suggests that this reflects the diving and flying sensations that may be experienced during hallucinations, just as these animals dive and fly themselves. Perhaps these animals helped the shaman journey into the "world below" and the "world above" as presented in the three-realm view of Hopewell cosmology by Charles, Van Nest and Buikstra (2004).

Shaman making pilgrimages to sacred places in nature, or on power/vision quests may explain the desirableness of exotic materials for making Hopewell objects, as explored by Carr in "Rethinking Interregional Hopewellian Interaction" (2005). Among historic Native Americans, 
journeying to a place of power in nature was a common practice (Carr 2005; Gill 1982).

Geological, hydrological, historic, or aesthetic qualities are all used to consider a place as sacred. Examples of such places include waterfalls, gysers, springs, large bodies of water, cliffs, caves, mountains, or even the outcrops of exotic materials (Bacon 1993; Carr 2005; Hudson 1976). The landscapes themselves could be viewed as sacred. The landscapes of the Yellowstone area, the Lake Superior region, the Appalachian Mountains, and the Gulf Coast all differ vastly from the Lower Illinois valley and southern Ohio in landforms, vegetation, and ecosystems. Carr (2005) states that while at such places, the people could access this power by spiritual activities like “...visions induced by exposure, fasting, chanting, prayers, and other means" or more external activities by "the collecting of special minerals, pigments, plants, and such." The power obtained in such journeys would help shaman in performing their tasks, such as in healing, influencing the weather and animals, and contacting spirits and supernatural entities. The materials that shaman brought back served as proof of the journey and experience, the power and beings they witnessed, and the power they themselves gained. The objects crafted from these materials may have aided in performing shamanic tasks and perhaps may have even appeared in visions before they were collected (Carr 2005). DeBoer (2004) makes the case for this based on the presence of bighorn sheep imagery in Ohio Hopewell artifacts. He proposes that while on a journey to obtain obsidian in Yellowstone, shaman observed bighorn sheep. They recorded what they saw in the form of platform pipes and a copper replica of a horn (Deboer 2004). While it is possible that the objects were merely proof of the journey, they may have been viewed as imbued with power themselves (Carr 2005). Such a journey could also have served as a transformative rite-ofpassage, something more common like a transition to adulthood, or something more special like the transition to becoming a shaman. Since healing played a major role in the responsibilities of a 
shaman, the journey may have been undertaken to heal a specific person or help the shaman be powerful enough to cure a certain powerful ill. Shaman may bring items of exotic materials to sick patients to help them experience the powerful and protective powers they experienced at such locations (Carr 2005).

Hopewellian goods may have also been used in the long distance buying, selling, and/or learning of ritual rites and practices (Carr 2005). Religious practitioners, shaman, or community leaders may have traveled to obtain ceremonial knowledge from others and brought exotic materials as payment and/or as the necessary ingredients for making ceremonial paraphernalia. Wright (2014) suggests that this was occurring at the Garden Creek site. Garden Creek is located in western North Carolina and has several earthworks. There is also a great deal of manufacturing debris from producing mica objects and quartz crystal bifaces, but there are not any of the finished products at the site. Wright suggests the possibility that the finished products were payment for learning ceremonial knowledge from Ohio Middle Woodland peoples (2014). An alternative hypothesis she discusses is that the finished mica and quartz crystal objects were manufactured and transported to Ohio ceremonial centers via pilgrimages. Carr (2005) also discusses this as a way exotic materials and goods were exchanged in Hopewellian interaction. Carr relates this to the idea of journeying to powerful places in nature, in the same way that the location is a place considered to have a special power. These ceremonial centers may have been built on places already considered powerful, with Carr (2005) citing unique landscape features at the locations of multiple earthworks sites. Objects brought to the site may have been for ritual deposition in caches or in mortuary contexts, or as payment for esoteric knowledge gained at the sacred places. 
Exchange between elites could also explain the flow of materials and Hopewellian objects, although exchange was probably just as common between ordinary people. Struever and Houart (1972) thought the goods communicated social prestige or that these goods would have been used as ritual paraphernalia used to reinforce prestige. These goods would have been reciprocally exchanged between elites at the ritual transaction centers that they proposed in their Hopewell Interaction Sphere model. Carr reexamines this idea in more updated terms as "symmetric exchange" of valuables and ritual items among elite Middle Woodland individuals of "approximate peer polities" (2005). Examples of such elites could include chiefs, chief-priests, "big men", ritual leaders, etc. The exchange of such materials between elites would have been an opportunity for these elites to demonstrate their knowledge and power to the other members of their community and that of the other elite. Another view of this exchange among elites is one of competitive exchange, where in the exchange was used to create a system debts and obligations, which strengthened their power by building alliances with other elites in the region (Carr 2005). Carr also explores the possibilities that spirit adoption and intermarriage may have had in the interregional exchange of Hopewell goods.

Middle Woodland habitation sites, while varying regionally (Ruby et al. 2005), were small hamlets resident to two to four families, with a focus of agriculture (Ruby et al. 2005; Smith 1992). Eastern Agricultural Complex (EAC) crops were a very important source of food for Middle Woodland communities. Included in this suite of plant foods are Chenopodium (Chenopodium berlandieri), sunflower (Helianthus annus), pepo squash (Cucurbita pepo), sumpweed (Iva anua), erect knotweed (Polygonum erectum), maygrass (Phalaris caroliana), and little barley (Hordeum pusillum) (Mueller 2013; Ruby et al. 2005; Scarry and Yarnell 2011; Smith 1992). White-tail deer were one of the most important sources of protein for Middle 
Woodland people, as well as fish, fowl, and small mammals (Scarry and Yarnel 2011; Styles 2011). Foraging activities, such as gathering nuts, provided an additional source of plant food (Abrams 2009). Structures were built using single wall posts using bent-pole architecture (Dancey 2005) and held a nuclear or extended family (Ruby et al. 2005; Smith 1992). In the lower Illinois River Valley, hamlets tended to occur near sources of flowing water, which for the region, would be the Illinois River or one of its tributaries (Ruby et al. 2005). Overall, floodplain mound sites were only seasonally occupied and left vacant except when in use for specific community activities (Dancey 2005; Ruby et al. 2005; Smith 1992).

Within the Lower Illinois River Valley, Middle Woodland sites can be classified as residential sites, logistical camps, bluff-top mound groups, and regional symbolic centers (King, Buikstra, and Charles 2011). The occupants of hamlet/village sites form residential communities, which are a group of people who are characterized by daily interactions with each other. In the context of the Lower Illinois River Valley, residential community sites would have been occupied by one to three family groups; Gardens of Kampsville, Apple Creek, and Macoupin are examples of residential sites (Ruby et al. 2005). Bluff top mound groups functioned as cemeteries for residential communities (King, Buikstra, and Charles 2011; Ruby et al. 2005). These mounds were smaller than their floodplain counterparts, and tend to consist of conical mounds rather than loaf-shaped ones. Sustainable communities are populations that have enough genetic diversity to be sustainable over long periods of time (Ruby et al. 2005). This was not formed by an obvious community structure, but would have been facilitated by the interactions at symbolic community gatherings (King, Buikstra, and Charles 2011). Bluff-top mound groups brought together the local community from small, symbolic communities whose identity was formed in exclusion to other groups (King, Buikstra, and Charles 2011; Ruby et al. 2005). 
Elizabeth, Klunk, and and Gibson mound groups are examples of bluff-top mound groups (Ruby et al. 2005). Floodplain mound sites, like Mound House, brought together a symbolic community that existed on a larger, regional scale. These regional symbolic communities would have incorporated multiple local symbolic communities or parts of them (King, Buikstra, and Charles 2011; Ruby et al. 2005).

Many Hopewell artifacts are made of extra-local minerals. More perishable materials may have been important as well, although these are hard to track to specific sources. Obsidian was the most distant material obtained and exchanged by Middle Woodland people. From where the greatest recorded deposits of obsidian artifacts are found in Ohio Hopewell sites to the nearest source of obsidian in the Yellowstone is a one-way trip about 5,000 kilometers. Knife River flint and Grizzly bear teeth were also materials transported from this region. Obsidian and Knife River flint were often used to make large bifaces (Struever and Houart 1972) while many bear teeth have holes drilled on them or otherwise modified (Struever and Houart 1972), for possible use as jewelry. Copper was a very prominently used material in making Hopewell artifacts. Copper was worked into items like celts and ear spools, but also into thin sheets shaped as anthropomorphic, zoomorphic, or geometric figures (Charles et al. 2004; Dancey 2005). While it was assumed for many years that copper was exclusively obtained from the Keweenaw peninsula in Michigan and Isle Royale in Lake Superior, chemical testing has shown that Appalachian sources of copper were also important (Hill et. al 2017). The Appalachians were more commonly the source of another important Hopewell material, sheet mica. This was cut into similar cutouts as copper artifacts, as well as circular "mirrors" (Charles et al. 2004; Struever and Houart 1972). Marine shell from the Gulf region was another important material (Struever and Houart 1972; Charles et al. 2004). While this is far from an exhaustive list of 
materials that were fashioned into Hopewell objects, it does highlight some of the more common and well-known types.

Earthworks are the other important aspect of Hopewell. Regionally, they vary by style, construction, and composition. The largest earthworks and mounds are found in Ohio (Charles et al. 2004; Dancey 2005). These include large circular or ovoid mounds, geometric enclosures, and embankments. These mounds tend to transform the very landscape around them. Hopewell earthworks in Illinois, such as Mound House, do not occur as large geometric enclosures but tend to be mounds and mound groups instead. Hopewell earthworks are not mere piles of dirt. Before the mound itself was constructed, the vegetation and, in some cases, the A-horizon of soil was stripped away to form a surface on which the mound was built. This is found in cases of both Illinois (Charles et al. 2004) and Ohio Hopewell mounds (Lynott 2015). The mounds themselves were constructed with various layers of soil, often having contrasting colors. Many Illinois mounds have the first layer of soil composed of a light sand, and the layer atop that soil is in the form of sod blocks (Charles et al. 2004), although there is much variation in the construction sequence of mounds and the types of soil they used (Charles et al. 2004). The sod blocks formed a ramp up to the center of the mound, where the rim of the crypt would be. Some of the crypts are lined with logs, one or two high from the crypt surface. A removable log covering also capped the crypt. In addition to the central crypt, mounds often had secondary burials along the periphery (Charles et al. 2004). A capping layer was placed over the sod block layer, completing the mound construction. Based on the special selection of soils for building Hopewell mounds, it is obvious that Middle Woodland peoples thought colors were significant, and soil visibility was important beyond just as part of a construction process that occurred before mortuary deposits. Based on the refilling and re-excavation of postholes with sand at mound 1 of Mound House, it 
was likely rebuilt or modified several times, reaffirming the importance of the soil, visibility, and its importance to the Middle Woodland people who made it (Buikstra et al. 1998).

While this study concerns Hopewell and the Middle Woodland period, the goal is not to redefine them or put forth a new way of understanding them. It is necessary that this study states how these terms are being approached for this thesis. As discussed, Hopewell is a term that has been used to describe a great number of things including artifact styles, earthworks, economies, religions, political organizations, etc. Following Charles and others (2004), this thesis approaches Hopewell as a term describing artifact styles, earthworks, and possibly practices associated with these. Middle Woodland is used to refer to a time period, as well as the array of cultures who existed during it. Many people during this period, to varying degrees, had Hopewell permeating into their daily lives, evidenced in the material record by the presence of distinct Hopewell goods and the presence of special mounds and earthworks. 


\section{CHAPTER II: THE MOUND HOUSE SITE, 11-GE-7}

The Mound House site (11-GE-7) is located in the eastern floodplain of the Lower Illinois Valley near the village of Hillview. Mound House (Fig. 1) is located upon an early Holocene sand ride adjacent to the main channel of the Illinois River and covers an area of approximately 5 hectares (Buikstra and King 2007). The site contains evidence of occupation beginning in the Early Archaic period, although the Middle Woodland component and mound activities dominate the site. Two radiocarbon dates from features at the Mound House have a calibrated range of $105 \mathrm{BCE}-238 \mathrm{CE}$ with a median calibrated date of $62 \mathrm{CE}$ (Buikstra et al. 1998). Two Middle Woodland mounds, named Mound 1 and Mound 2, are present. Previously, based on early $20^{\text {th }}$ century maps by Woermann (1905), the site was thought to have an additional three mounds, although this seems to have been a misinterpretation of the map (King, personal communication). Additionally, an open, level space directly adjacent to the mounds may have functioned as a plaza or gathering space. In prehistoric times, a backwater lake abutted the sand ridge just southeast of Mound 1. A group of possible structures north of Mound 1 has been designated as a habitation area, where people stayed during the relatively brief seasonal occupations of the site. Remote sensing data and excavation has revealed the presence of structures and postmolds, yet how many structures they represent is unclear (King, Buikstra, Thornton, and Demarco 2011; Thornton 2014). This area contains large concentrations of lithic debris, ceramics, and faunal materials, which has been interpreted as this area being used as an activity space (King, Buikstra, Thornton, and Demarco 2011). Floodplain mound groups like Mound House, and others like Kamp and Peisker, are thought to have served as regional symbolic centers for Middle Woodland people (King, Buikstra, and Charles 2011). These sites would have served as gathering places for a regional symbolic community for ceremonial and 
communal activities. While evidence suggests that Mound House had a great deal of ritual complexity and Middle Woodland activity, there is not an especially abundant or notable amount of Hopewell artifacts from exotic materials. Blades and blade cores are very recognizable at the site, and make up one of the most abundant artifact classes at Mound House (Buikstra et al. 1998). Due to the high number of blade cores compared to the number of finished blades at the site, Morrow (1989) believes that blade production was a centralized activity for the Middle Woodland people at Mound House.

Mound 1 was the site of a historic residence from 1873 to 1940 (hence the name, "Mound House"), which had one wooden house and two outbuildings (O'Briant 1996). The construction of these buildings, which included a cellar and privy pit, damaged the mound on which they were built. However, the presence of buildings on Mound 1 did spare it from agricultural plowing. Mound 2 was subject to a great deal more damage. During the early $20^{\text {th }}$ century, a levee was constructed in the western portion of the site, and Mound 2's superstructure seems to have been used as fill. This, and subsequent agricultural plowing, has severely damaged the mound, leaving nothing visible except a slight rise in the sand ridge (Buikstra and King 2007). Despite this, a significant amount of subsurface integrity remains to serve as a source of information on Middle Woodland mound centers and it was placed on the National Register of Historic Places on September 1, 1978 (Buikstra et al. 1998). Early investigations of the site included surface surveys in the early 1960's, 1976, and 1986. A trench was also excavated in the western side of Mound 1 during the 1986 survey. Excavations at the site have primarily been conducted by the Center for American Archeology as part of university and education programs. Excavations from 1990-1999 were focused on the area around Mound 1 and the plaza area. Excavations during the period of 2001-2006 were directed to answer questions about Mound 2, particularly where its 
boundaries are and what artifact types are present in that portion of the site. During the excavations of both mounds, excavating the crypts, human remains, and burial goods were not part of the research design and to date, human remains have not been encountered (Buikstra et al. 1998).

One of the primary goals of the Mound 1 excavations was to understand the construction sequence. The excavations also aimed to understand the pre-mound activity at Mound House. A large number of pit features, post-molds, and artifacts demonstrate that there was a significant amount of Middle Woodland activity at the site prior to mound construction episodes (Buikstra et al. 1998). Buikstra and others (1998) identify that the first phase in the mound construction was the deposition of a series of sterile sandy loam soils onto the ridge surface. This sand layer is distinct from the other soils. Extending down from this layer there are a number of postholes. The fill within these postholes is layered and compacted with alternating types of fill, suggesting that the posts were removed and set back within the same holes several times, during several reconstruction episodes for the structure. The ramp forming the raised surface to what would be the burial crypt is comprised of inverted sod blocks originating from flood deposits from a close proximity to the river (Charles et al. 2004). The mound was then capped with a yellow, clayey silt loam layer of fill (Buikstra et al. 1998). The post-molds in the layer of yellow sand are found in the southern margin of the mound and form concentric rings. These rings surround the layer of yellow sand and seem to represent three to four arcs (Buikstra et al. 1998). The post-molds are regularly spaced approximately $75 \mathrm{~cm}$ apart and have an average depth of $17 \mathrm{~cm}$. Charles and others (2004) suggest that due to the wide spacing and shallow depth of the postholes, they were used to create a separation of space, rather than support a roofed structure. This could have functioned as a ritual screen to mark of the sacred space represented by the yellow sand deposit 
and limit access to certain participants (Buikstra et al. 1998). The existence of this structure suggests an unusual level of ritual complexity at Mound House compared to other floodplain mound sites. However, more of these structures may be present at floodplain mound sites but have yet to be excavated. The deconstruction and reconstruction of the structure suggests that this was part of a ritual cycle for the people who made and used it.

As with Mound 1, the Mound 2 area contained post-molds present on pre-mound surface. It also seems that the surface on structures in Mound 2 were built is roughly analogous with the structures on the light sand surface under Mound 1. Unlike with Mound 1, the post-molds in Mound 2 seem to belong to two structures, which are thought to have been bent-pole structures with roofs rather than a screen or partition (King and Buikstra 2007). Excavations during the 2001-2006 field seasons also revealed that Mound 2 had a complex internal structure, despite the intense damage to the mound from being used as levee fill and from agricultural plowing. Light colored sands do not make up the initial phase of construction for Mound 2. While present in certain units, it does not underly the entire mound. This may be due to a different choice for soil use and contrast, comparing it with Mound 1. Mound 2 may have built in a way that horizontally added onto an initial construction that may have occurred over the light soil that is present at the base of Mound 2. Like Mound 1, Mound 2 had a sod ramp and a capping layer of a different soil type (King and Buikstra 2007). 


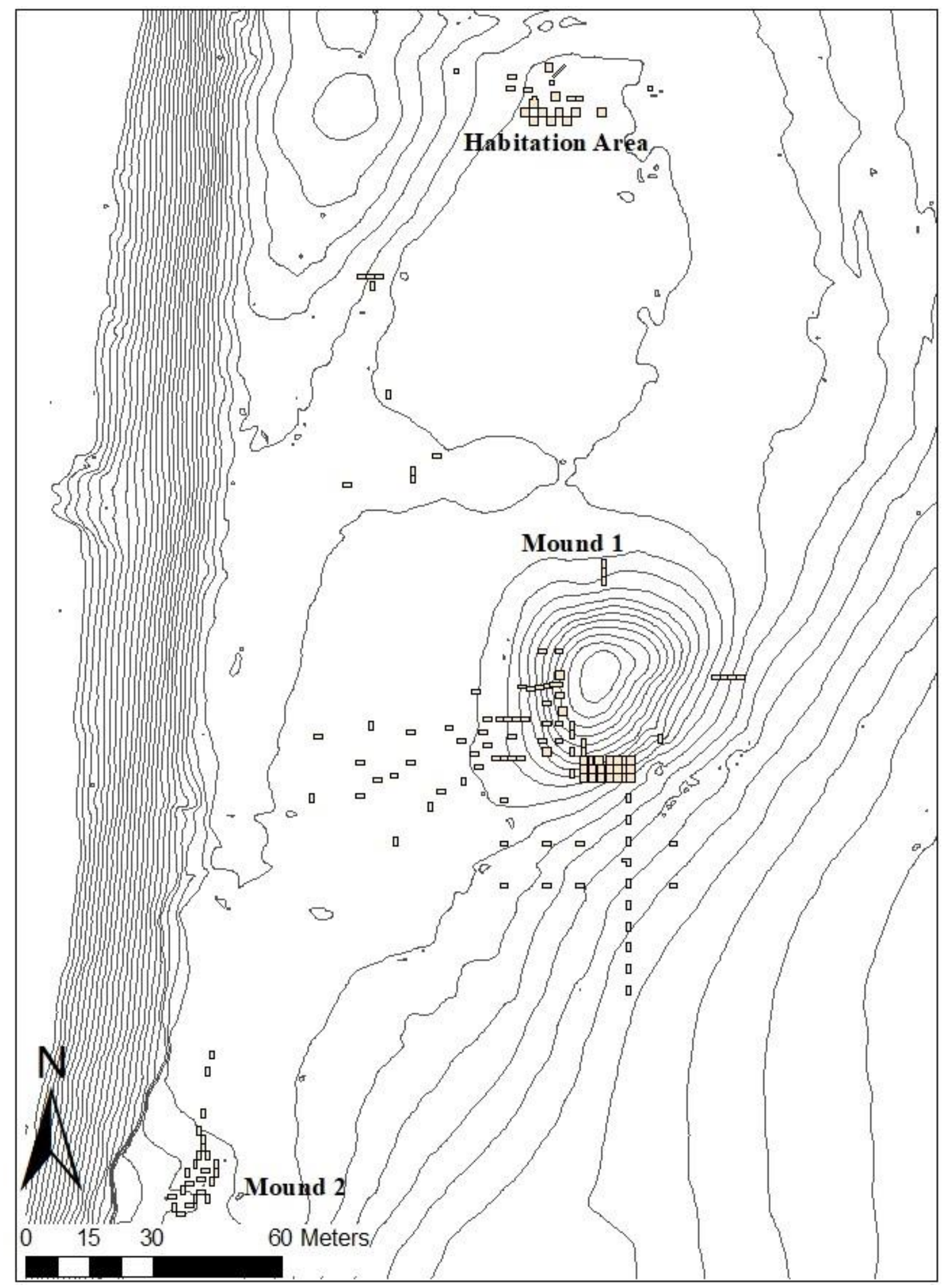

Figure 2. Map of the Mound House Site with Units and Labels of Mounds and Areas. 


\section{CHAPTER III: PREVIOUS ANALYSES OF HOPEWELL BLADES}

Hopewell blades are but one type of blades produced in North American prehistory.

Clovis lithic technology included blade-making, which saw continued use into the Early Archaic period with Dalton, Kirk, and Bifurcate assemblages (Yerkes 1994). After this time, bifacial technology became the dominant lithic reduction strategy in eastern North America. Through independent invention blade-and-core technology resurfaces three times in Midwest Prehistory, during the Terminal Archaic (1700-600BCE), the Middle Woodland (100BCE-400CE), and the Mississippian (1000-1300CE) (Yerkes 1994). Hopewell blades are a version of the formalized core-and-blade reduction strategy for producing lithic tools (Fortier 2000; Yerkes 1994). A core is a prepared block of flint for the removal of flakes. Blades refer to the formalized type of flakes struck from a specialized, prepared core. They are defined as having a length at least two to three times its width, edges that are mostly parallel, and have flake scares that run parallel to their longitudinal axis (Miller 2015; Nolan et al. 2007; Yerkes 1994). Hopewell blade technology does have regional variation, with those in the Illinois River Valley being wider and longer on average than those in Ohio sites (Fortier 2000; Greber et al. 1981; Miller 2018b; Yerkes 1994). This is likely due to differences in production technique. Illinois blades also have more retouch than their Ohio counterparts. Fortier (2000) identifies a number of retouched blade tool forms in the American Bottom, including blunt drills, end scrapers, side scrapers, gravers, perforators, denticulates, becs/spurs, and hafted knives/scrapers (Fortier 2000). Some scholars have tried to distinguish between "blades", "bladelets", and "microblades", based on width, length, production technique, and cultural context (Kay and Mainfort 2014; Tixier 1974; Yerkes 1994). The use of the terms to "blades" and "bladelets" by different scholars both refer to the same class of Middle Woodland technology. This study does not seek to challenge the distinction some have made 
between terms or formalize one term or the other. For the purposes of this study, the tools produced by Middle Woodland core-and-blade technologies will be referred to simply as "blades".

Blade technology in the Middle Woodland may have begun out of the Early Woodland "Fulton technique" in the Lower Illinois River Valley as described by Montet-White (1968) and others (Fortier 2000). This technology may have been spread to Ohio Middle Woodland groups by those in Illinois, since the earliest dates for blades in Ohio coincide with the presence of Ohio Flint Ridge flint bladelets in the Lower Illinois River Valley (Miller 2018a). Blade technology quickly disappears with the collapse of Hopewell and are not present in Late Woodland contexts (Fortier 2000; Miller 2018a).

Since blades existed alongside the bifacial stone tool technology used by Middle Woodland societies, the production and function of blades has been a point of interest. Nolan and others (2007) note that blades have been described as tools for the production of ritual crafts and tools made by expert craftsmen. Nolan and others (2007) examine the lithic assemblage at the Turner workshop, which is the largest blade production site in Ohio. It is adjacent to the Turner Earthworks, a major Ohio Hopewell mound and earthworks site in the Ohio Hopewell core region. The site has produced over 7,000 blades, cores, blade fragments, and related debitage (Nolan et al. 2007). The research design of that study was to measure the skill of the knappers who produced the blades at Turner. Nolan and others (2007) assumed a craft specialist would be skilled and efficient, and this would be reflected in the lithic assemblage at Turner. A number of variables were selected to test the skill level of the people who used the site. Raw material selection and the amount of heat treatment present were selected in order to measure the skill of the knappers in selecting the best materials suited for producing blades. Additional variables 
examined included the amount of cortex present on the blades, blade metrics, dorsal facet count and the blade cross section, blade terminations, blade condition, and modification. Variables used for the blade cores measured the number of blade core platforms, removal faces, and platform angle and blade core length, width, thickness, and shape (Nolan et al. 2007). These variables were put through a number of statistical tests in order to measure the skill and efficiency of the production process. Due to the variability in metric attributes and their platforms, as measured by the coefficient of variation, and a high degree of error in blade production, the authors conclude that the blade makers at the Turner Workshop were not especially skilled, suggesting that they were not specialists (Nolan et al. 2007).

Blades certainly functioned as cutting tools, however, that may not have been their sole or primary function. Morrow (1987) argues that blade production technology had meaning in regional social systems as an informational component in the Hopewell Interaction Sphere model. Morrow's work is primarily focused on the distribution of Cobden chert during the Middle Woodland period. Cobden chert outcrops in southern Illinois, yet Morrow (1987) sees that the major concentrations of artifacts made from it occur north in the central Illinois Valley. This suggests it was a prized raw material for Middle Woodland people. Blades, however, are a fairly disposable tool, so the widespread use of Cobden chert for blade production is what Morrow refers to as "conspicuous consumption" (1987). Morrow (1987) also argues that blades do not reflect any technological requirement but were a production style choice spread throughout the Hopewell Interaction Sphere. Odell (1994) also argued that blades functioned as a Hopewell item, due to their abundance in ceremonial contexts. In burial mounds, blades were found more often as grave goods than bifaces and were often found in the burials of older women (Odell 1994). 
Yerkes (1994) used microwear analysis to investigate the Murphy site, a Middle Woodland site in Ohio. Evidence from the site suggests that it was a habitation site (Yerkes 1994). Looking at the blades, about a third of those with use-wear were used for cutting meat or fresh hide. Those categorized as cutting antler/bone, working wood, and incising stone made up about $15 \%$ of utilized blades each. The remaining percentage of blades with use-wear were equally distributed among being used for scraping hide, cutting plants, or were used on unidentified materials (Yerkes 1994). While some of the blades in Yerkes study were used for engraving stone, he notes that none seem to have been specifically used to cut mica, an important Hopewell material (Charles et al. 2004; Dancey 2005; Struever and Houart 1972). Nor do any of the blades exhibit use-wear indicative of cutting copper or shell, also important materials widely circulated in Middle Woodland communities (Charles et al. 2004; Dancey 2005; Struever and Houart 1972).

Yerkes (1994) compares the results from Murphy to two mound sites, the Newark and Marietta sites. Of Newark's utilized blades, 50\% were used for cutting meat, and the rest are equally distributed among scraping hides, bone and antler, wood working, and cutting plants. At Marietta, 20\% were used for cutting meat and the same amount for scraping hide, $30 \%$ were used for working bone or antler, and the rest were equally distributed (at about 10\% each) for cutting plants, incising stone, and working unknown materials (Yerkes 1994). In all the assemblages examined in his study, Yerkes notes the wide range of tasks that the blades were used for. Another wide trend is that all the microwear seems to be weakly developed, which would suggest they were used expediently and then discarded. Yerkes sees scant evidence that blades were used as a specialized tool for craft production. Rather, they seem to be a standardized tool used for a wide range of activities (Yerkes 1994). 
The Ft. Ancient site was the subject of a use-wear analysis study by Miller (2015). Unlike the Murphy site which Yerkes (1994) examines, Ft. Ancient is a large Ohio Hopewell earthworks site. Located on a terrace above the little Miami River, the earthworks form a wall some 5.7km, which is divided by 67 openings and encloses the top of the hill (Lynott 2015; Miller 2015). Miller examines seven different areas of the site and finds that the types of activities blades were used for varies in intensity in each of these areas. Some areas of the site show that craft production played an important role, such as stone use-wear making up over $35 \%$ of the usewear in some contexts (Miller 2015). However, in all of these contexts, blades were used for a large range of activities, including cutting meat, working hide, antler, bone, wood, soft plants, stone, and even minor amounts of shell. The most common motions of use employed across the various contexts are sawing and scraping, with graving making up a significant percentage in some instances. Drilling is present in only one context, where it makes up $9 \%$ of the motions employed. Four of the seven contexts at Ft. Ancient were used for craft production of Hopewell items, based on both use-wear data and contextual evidence (Miller 2015). Miller (2015) arrives at the same conclusion that Yerkes (1994) did, that they were not a tool created for producing Hopewell crafts, but were a multi-purpose tool that served many functions based on the variety of use-wear present across the site. However, Miller does emphasize that blades at Ft. Ancient did serve an important role in the production of Hopewell crafts (2015).

A more recent study by Miller (2018) examines use-wear from two sites in close proximity to the Stubbs Earthworks in Ohio. The first of these two sites is the Smith site, which seems to contain short-term specialized structures or activity areas that had ceremonial function for the Stubbs earthworks. The second site, the Circle Overlook site, is interpreted to have served as a domestic space for local and extra-regional visitors to the site based on ceramic evidence 
(Miller 2018b). At Smith, bone/antler use-wear was the most commonly represented class, a number of which were modified and used as gravers. This is very unusual for Ohio sites (Miller 2018b), this type of blade modification is more commonly seen in southern Hopewell assemblages like those in Tennessee and North Carolina (Kay and Mainfort 2014; Kimball 1992). Meat, fresh hide, dry hide, soft plant, wood, and stone working are less common but still represented forms of use wear (Miller 2018b). Bone/antler was also the most common form of use-wear at Circle Overlook. The other classes of wear mentioned at Smith were also present at Circle Overlook, with the exception of wood. With the large amount bone/antler working being done at Stubbs, Miller thinks this reflects a large amount of symbolic craft items being produced. The stone working present also reflects the production of symbolic Hopewell craft items. While craft production was also evidenced at Ft. Ancient (Miller 2015;2018b), materials not present at Stubbs were being worked. This leads Miller (2018b) to suggest that while blades performed a role in producing craft objects at Ohio Hopewell earthworks sites, there is not a standardized pattern of use within those contexts, but instead varies from site to site.

The Paint Creek Lake Site \#5 is a surface collection site in Ohio that was the subject of a 1998 study by Lemons and Church. Based on the collected assemblage prior to the site's inundation, it is thought to represent a small, open habitation. Lemons and Church (1998) break the use-wear down into a number of categories based on blades that appear to have more than one type of use-wear or could be placed in more than one category. However, hide-working activities make up over half the use-wear present. Meat processing use-wear makes up most of the rest of the use-wear, while activities involving hard materials including bone, shell, and wood make up the smallest percentages of use-wear. Use motion could be determined for about half of the utilized blades and motions include scraping (19.2\%), cutting (13.5\%), skinning (5\%), 
sawing (1\%), and graving (1\%). The authors conclude that the blades in this assemblage were used for a variety of non-specialized tasks (Lemons and Church 1998).

While there are multiple use-wear studies regarding Ohio Hopewell blades, the only usewear study of Illinois blades was conducted by Odell (1994). However, Odell uses a more generalized categorization of wear, in comparison to the other studies examined, based in lower magnification microscopic analysis. He divides the use-wear into seven categories: soft animal (flesh, hide, skin, fish), soft vegetative (tubers, plant stems), less resistant medium (soft wood such as pine), more resistant medium (hard wood), organic hard (for example, bone), organic very hard (dry antler), and inorganic hard (earth, stone). Odell mentions that it is often useful to further condense these categories into soft, medium, and hard (1994). These generalized categories are the result of using a low magnification technique. This makes it difficult to compare to the other studies examined, which use different microscope technology and higher magnification. Odell (1994) conducts use-wear at two different sites, Smiling Dan and two spatially discrete contexts at Napoleon Hollow. The author likens Smiling Dan as a habitation site similar to the Murphy site (Yerkes 1994), although slightly larger with more substantial habitation structures. Retouched blades are used for a diverse range of activities, which fall into the hard and hard-medium categories. Odell attributes this use-wear to butchering and toolmaintenance activities. Unretouched blades were used on primarily medium and hard materials (the majority of which Odell attributes to wood and bone), with another quarter of them being used on soft materials. Napoleon Hollow is a floodplain site, which Odell (1994) mentions seems to be a habitation site for prominent individuals associated with Hopewell ritual practice. Retouched blades from this site were used for a range of tasks and are roughly equally distributed among soft animal, resistant medium, and organic hard. Unretouched blades also 
were used for a range of tasks, but the author notes soft materials making up nearly half of the use-wear. As such, there is a significantly larger portion of soft use-wear present at Napoleon Hollow than at Smiling Dan. Odell also examines samples from the talus slope of Napoleon Hollow, at the base of the bluff upon which the Elizabeth mound group sits. Here, the majority of the blades were used on soft materials, although there was some medium and hard use-wear present on blades as well. While Odell does see the wide range of activities that blades were used for, he also argues that they played an important role in mortuary preparation, based on their presence in burials at Elizabeth mounds and in ritual areas of the sites he conducted analysis at where he presumes mortuary ritual was occurring. Odell determined the use of blades for mortuary preparation by the plant cutting use-wear present on blades at mortuary sites, which he thinks were used to create burial mats. Odell (1994) thinks that blades had an important role in ceremonial activities, but their functioned varied by context.

Kay and Mainfort (2014) conduct use-wear analysis to blades from the Pinson Mounds site in Tennessee. Pinson mounds is a large Middle Woodland site thirteen mounds, a geometric earthwork structure, and short-term ritual activity areas (Kay and Mainfort 2014). They employ a different approach from the studies discussed so far. A microscope which Kay and Mainfort claim is much better than used in similar studies, with polarized lights and Normaski optics, is used to in identifying use-wear (2014). Despite this different technique, it produces similar results and categories to Yerkes' (1994) study. They also use a production chain approach to understanding tool function, and class use-wear into tool type categories rather than ones based on types of material worked. These categories are: blanks, gravers, burins, knives, scraper, debitage, and other. The most common tool they identify is the burin, which makes $33 \%$ of the Pinson mounds assemblage. Bone, antler, and wood are noted forms of use-wear for these burins, 
but Kay and Mainfort do not discuss the distribution of this use-wear in the assemblage. Gravers are similar to burins in function and make up 5.6\% of the use-wear. Kay and Mainfort's knife category makes up $8.8 \%$ of the use-wear in the assemblage. Three types of use-wear were identified in the knife category: soft plant, hardwood whittling, and butchery. Scrapers are the second-most common tool form making up $9.6 \%$ of the use-wear and are also divided into three subgroups. Blades used as scrapers were categorized as scraping hide/soft plant, wood or other hard plant material, and scrapers used like planes on wood or possibly bone or antler. The other category contains tools with unique functions or only have hafting use-wear. Kay and Mainfort (2014) placed blades that did not have use-wear into the blanks or debitage category. In general, Kay and Mainfort see a large number of blades being intentionally snapped to create burins and other tools, but still fulfill a wide range of technological needs (2014).

Another study of Hopewell blades outside of the Ohio and Illinois region was conducted by Kimball (1992). This was an analysis of blades from two different sites, Icehouse Bottom in eastern Tennessee and Garden Creek in western North Carolina. Icehouse Bottom is an open-air habitation site while Garden creek has both mound and habitation areas. Kimball identified that the blades were used for a variety of tasks at these sites, these include: light butchery, meat cutting, hide cutting, bone/antler working, wood working, and wear from soft stone such as mica or soapstone (1992). Bone and antler working included the motions of sawing, graving, planning, and boring. Wood was whittled and sawed, while the stone use wear exhibited motions of cutting or incising. He notes that $30 \%$ of the blades in his sample had been used for more than one task. Kimball (1992) also notes that some blades appear to have been intentionally broken to serve as gravers, just as with the blades at Pinson mounds (Kay and Mainfort 2014). 
Of the studies discussed that use use-wear analysis to investigate Hopewell blades, the common theme is that the authors conclude that they functioned in a variety of tasks and contexts. Some note the role blades had in craft production (Miller 2015) and in mortuary ritual (Odell 1994), yet they were not exclusive to this function. Blades seem to have applied to any task by Middle Woodland people so long as blades could fulfill the desired technological requirement. Blades do not appear to have been made by specialists either, as evidenced in studies measuring the efficiency of production (Nolan et al. 2007). Current studies suggest that despite being synonymous with the spread of Hopewell during the Middle Woodland period (Fortier 2000; Kay and Mainfort 2014; Miller 2018b), blades are not a specialized product for Hopewell crafts or ritual practices. 


\section{CHAPTER IV: A BRIEF HISTORY OF USE-WEAR ANALYSIS AND METHODOLOGY}

Lithic use-wear or microwear analysis is a technique based on the observation that when stone tools are utilized, wear and damage patterns will be produced on that tool that are specific to the material the tool was used on (Kay and Mainfort 2014; Keeley 1980; Miller 2015; Odell 1994; Yerkes and Kardulias 1993). Wear can occur as edge damage, striations, and polish. Wear results from both the material the tool contacts and the motion in which it was used. These wear patterns are distinct from other material types and natural, post-depositional process. Wear patterns on experimentally produced tools are used as analogs for producing wear patterns for the identification of microwear on lithic artifacts. This makes microwear analysis one of the most useful techniques for identifying stone tool use in the archaeological record since it connects the material remains of the past to the lives of the people who made, used, and disposed them (Stemp et al. 2016; Yerkes and Kardulias 1993). Use wear analysis has been used to address questions about economic activities, social organization, settlement patterns, subsistence patterns, culture change, and more (Keeley 1980; Kimball 1994; Stemp et al. 2016; Yerkes and Kardulias 1993). Use-wear analysis provides a way to identify the function of an individual tool, which provides a means to assess actual tool function as opposed to assuming function based on attribute characteristics or comparison to modern tools (Keely 1980; Yerkes and Kardulias 1993). This allows for the interpretation of the types of activities people at a site or site context were engaged in. Since use-wear analysis requires examining individual tools, the technique can be time intensive, especially for sites with large assemblages.

Experiments have established wear patterns on a very broad range of materials and motions. Often the tools used in the experiments are used to create objects in the archaeological record or described in ethnographic accounts to provide as accurate of an analog as possible for 
comparison to artifacts (Stemp et al. 2016). Stone tools used on materials to mimic a certain motion, yet are not used to produce anything, are considered to be less useful in comparing them to archaeological examples. For example, compare arbitrarily sawing on wood to cutting a groove in a piece of wood to haft a tool. Since the latter activity would have been undertaken by prehistoric people, the wear patterns on the experimental tool would be more alike to those in the archaeological record compared to the tool used to produce nothing.

Use-wear analysis began with the pioneering work of Semenov (1964). While macroscopic examination of stone tools and the use of hand lenses and low-power microscopes had occurred before Semenov's work, these did not have the same impact. Semenov's experiments took place in the 30's-50's, although his work did not make its way into Western archaeology until his book Prehistoric Technology was translated from Russian in 1964 (Stemp et al. 2016). Semenov primarily used a low-power stereographic microscope (20x-40x magnification) combined with carefully controlled lighting, surface, treatments, and photography to identify and record use-wear patterns (Semenov 1964; Stemp et al. 2016; Yerkes and Kardulias 1993). His use-wear identification techniques were paired with an experimental program from which to compare the use-wear on artifacts to (Yerkes and Kardulias 1993). Some of his methods were difficult for other scholars to replicate, leading some to form different techniques later on in response (Keeley 1980). This difficulty in replicating Semenov's results could be partially due to its translation from Russian to English. Odell (1977) used a lowerpower stereographic microscope with angled lighting to make identifications of use motion and the hardness of the material based off of edge damage and striations on the tool (Odell 1977; Stemp et al. 2016). In contrast to this approach, Keeley's (1980) high power magnification technique not only looked at the edge damage and striations, but also edge rounding and polishes 
in identifying tool function. Keeley's high-power technique also used incident lighting instead of the angled lighting Odell used. High-power techniques have seen more widespread use than lowpower techniques since the former technique can more reliably be used to identify contact material. This does not mean that it is necessarily better than low-power microscopy, using both high and low magnifications is useful in identifying wear. The significant advantage that lowpower microscopy has over high-power techniques is that less time is required to prepare and examine the specimens.

During the 1980's a third approach to use-wear used scanning electron microscopes (SEM) to conduct use-wear analysis. SEM is advantageous because of the high degree of magnification and resolution it possesses and its depth of field (Stemp et al. 2016). One major drawback of SEM is that it requires the artifacts to be coated, and, at the time, also was restricted in the size of artifacts it could examine. Artifact coating is also used for other forms of microscopy (such as high-power), but this process does have the potential to obscure use-wear. There was also a great deal of experimental studies and replication of tasks during this time period (Stemp et al. 2016; Yerkes and Kardulias 1993). Most of these studies used chert and flint for the tools in these experiments, but a handful employed obsidian, quartz, quartzite, basalt, shale, and groundstone tools in their experimental studies (Adams 1993; Hurcombe 1992; Kajiwara and Akoshima 1981; Price-Beggerly 1976; Sussman 1985). It was around this time that the mechanisms of wear formation began to be debated in depth. It was unclear if the formation of polish was an abrasive process, an additive process, the result of a chemical reaction, or a combination of abrasive and additive processes (Kamminga 1979; Stemp et al. 2016). This continues to be a debated topic among use-wear analysts due to the conflicting results produced by studies. Blind tests measuring the objective ability of the observer to identify use-wear also 
took place in the 80 's, with varying degrees of success. Due to the inconclusive results of some of these tests, there was some debate within the discipline of how reliable a method use-wear analysis was. Some of the tests that failed were the result of poor methodology, such as an insufficient amount of time experimental lithics were employed as tools (Stemp et al.2016). The experience and ability of the subjects in the test is also a factor that could have lead to the inaccurate results generated by these studies. Attempts were made at creating at quantifiable way to measure and identify use-wear (Keely 1980; Stemp et al. 2016), but these were mostly unsuccessful.

According to Stemp and others (2016) the 1990's saw a substantial amount of use-wear studies, which continued to increase archaeology's understanding of tool use, in addition to experimenting with more diverse types of stone and materials worked. It was also during the 1990's that Kimball and others (1995) used atomic force microscopy (AFM) in a successful trial attempt to quantify differences in use-wear. Since the 1990's, use-wear analysis has seen continued use by archaeologists as a tool for understanding the functions of stone tools. Stemp and others (2016) note that little change in methodology has occurred during this time since new practitioners of use-wear analysis use the methods and models of their predecessors and mentors. However, these authors also note that new use-wear scholars use a combination of use-wear methods, such as low-power microscopy, high-power microscopy, SEM, etc. Unsurprisingly, computer and engineering technology has been increasingly applied to use-wear studies, largely as attempts to quantify differences between polishes caused by contact with different types of materials (Stemp and others 2016). Laser scanning confocal microscopy is a one such technological application that shows promise in distinguishing quantitative differences between polishes (Evans and Donahue 2008). Issues such as use-wear formation and how to conduct 
blind tests remain unresolved. One recent development in use-wear analysis has been the determination that hafting stone tools and prehension from gripping them by hand leaves identifiable wear patterns (Rots 2005). While more traditional use-wear is sufficient to determine the tool's function, tracing the hafting wear can give a more in-depth view of how a tool was used by potentially identifying the hafting system that was used. It can also guide questions regarding a tool's curation and discard (Rots 2005). Blind tests have confirmed that hafting and prehension wear is distinct enough to be readily identifiable (Rots et al. 2006).

Over three-hundred and fifty blades have been recovered from excavations at the Mound House site. For this study, one hundred blades were sampled in order to conduct use-wear analysis. The goal was to sample a substantial number of blades from both mound area and habitation/non-mound area contexts. From the mound area, 39 blades were analyzed and from the habitation/non-mound area, 61. Of the 39 blades in the mound area, all were from the Mound 1 excavations, none of the Mound 2 blades made it into the sample. This is due to a sampling error in which some blades from the habitation area were mistaken as blades from the mound 2 area that are both from excavations that took place in the same year. Each batch of blades was photographed prior to analysis in order to assist in noting areas with use wear and retouching and help keep track of the blades during the cleaning process. Following Miller's (2015) technique, the blades were cleaned using liquid soap and water in an ultrasonic cleaner, which removed surface adherents which may mislead interpretations of use wear. This removes materials clinging to the surface, such as dirt and oils, but does not affect use wear or remove visible residues. A number of the blades had a coat of B-72 for labeling accession number written on them. This can obscure or even imitate use wear polish, and as such had to be removed for most of the blades. Rubbing alcohol completely removes the polish 72 from the surface and 
evaporates itself, leaving no visible residue on the artifact, even at higher magnifications. After washing and air drying, the sample was analyzed using an Olympus BX51M microscope, under magnification ranging from 50-500 times, with photomicrographs taken of notable areas with use-wear. Keeley's (1980) method of use-wear analysis was followed, as well as Miller (2015, 2018) who uses this same method. The Keeley method examines microscopic polish, striations, and edge damage which form from contact with different materials and from different motions of use. High-power microscopy is used to conduct this use-wear analysis approach. The identification of use-wear on archaeological artifacts is based on similarities with modern, controlled experiments that replicate these motions on analogous materials (See Van Gijn [1990] for photos of use-wear from a wide range of materials and motions). Every attempt was made to examine the entirety of every blade, including the edges, dorsal ridges, and both dorsal and ventral faces. Use-wear was recorded using detailed notes, the position of the wear being described by the face (dorsal or ventral), position on the blade relative to the platform (end, distal, medial, proximal, and top, right or left edge), and position relative to distinctive features such as median ridges, retouching, prominent edge damage, etc. 


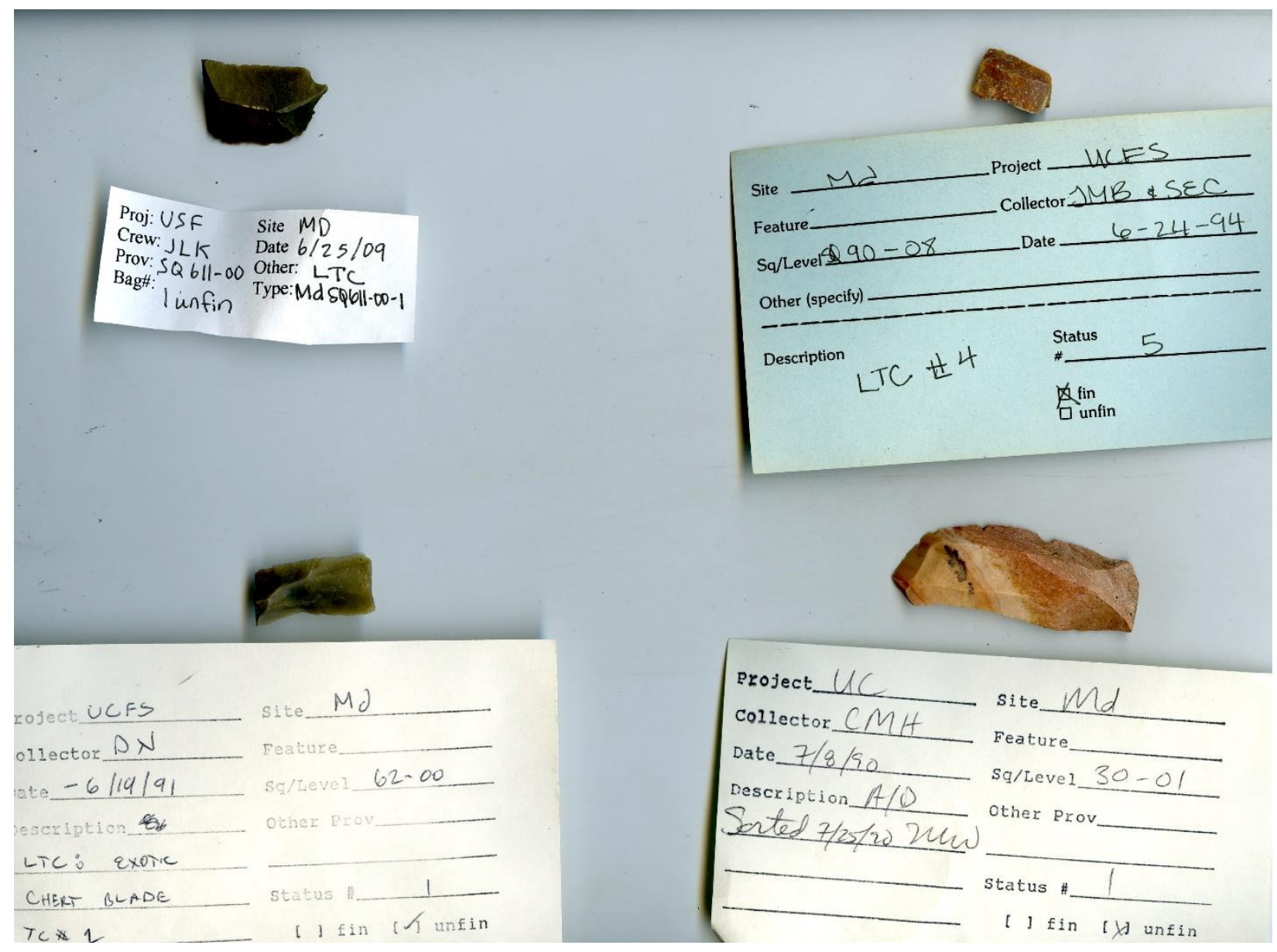

Figure 3. A Selection of Blades and Blade Fragments from Mound House. 


\section{CHAPTER V: RESULTS}

From the sample of Mound House blades, $56 \%$ had traces of use-wear. In the habitation area, there was a nearly equal amount of used and unused blades (Table 1.). When compared to the mound area, there seems to be a concentration of unused blades in the habitation area. The utilized blades were used to process seven different types of materials: meat, bone/antler, dry hide, fresh hide, wood, soft plant, and stone. Nine blades were utilized but were unidentifiable due to the wear being insufficiently developed. A total of 8 blades had wear resulting for hafting or prehension. Meat (Fig. 3d, Fig. 9) was the most abundant type of wear present (Table 2). Bone and antler use-wear was the most represented category besides meat. While experimental studies have shown the two can be distinguished (Van Gijn 1990), there were many blades in the Mound House assemblage that could be identified as either. Lumping bone and antler use-wear (Fig. 3c, Fig. 5) into a single category proved to be more meaningful than trying to separate them since these materials were used in very similar ways. Dry hide working (Fig. 6), fresh hide working (Fig. 7), and wood (Fig. 3b, Fig. 12) use-wear were also well represented categories. There was one instance of soft plant use-wear (Fig. 10) and stone working use-wear (Fig. 3a, Fig. 11). This instance of stone cutting/incising does not seem to match use-wear that would result from use on mica. Mica, due to being a soft stone, would have left use-wear that would have extended further up the blade than what was observed in this sample. Likely, the stone use-wear observed here was the result of an undetermined harder stone, such as pipestone. The edge damage is relatively minimal, so it was likely used in some sort of engraving motion. 

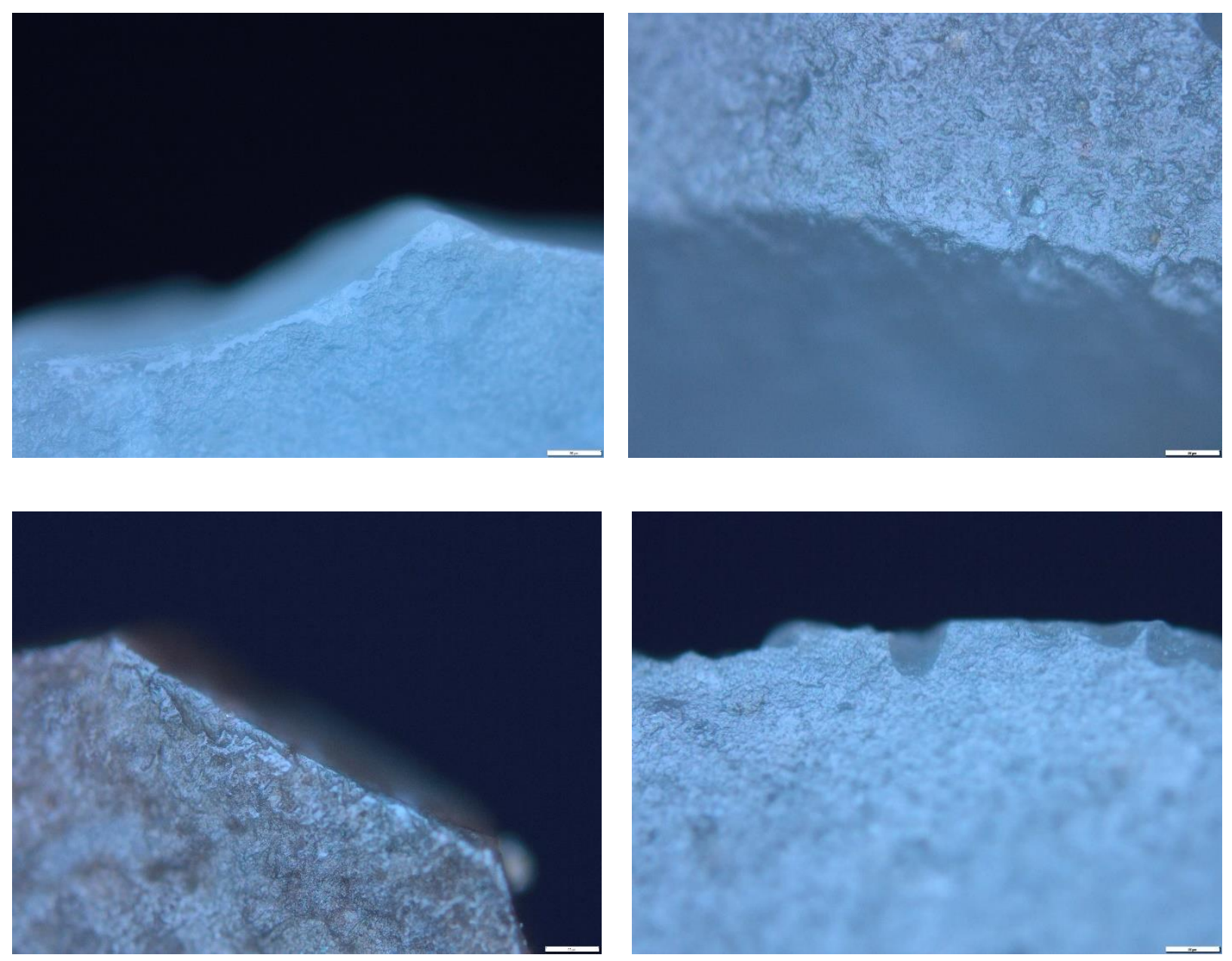

Figure 4. Photos of use-wear on blades a. Stone incising use-wear (200x) (upper left), b. Wood drilling use-wear (200x) (upper right), c. Bone sawing use-wear (200x) (Bottom left), d. Meat use-wear (200x) (Bottom right).

In addition to use-related activities, $17 \%$ of the utilized blades had use-wear that is distinctive of hafting or prehension. Two of the blades with hafting have fresh hide use-wear and two more have meat use-wear. Soft plant and wood use-wear are present on two different blades that have hafting use-wear. Only two of the blades were used on more than one type of material, excepting hafting wear. Meat and bone use-wear was present on one blade, which could be the result of butchering. The other had meat and dry hide use-wear. In general, the use-wear on the blades was poorly developed and identifiable portions of polish tended to be small. The lightness 
of use-wear and the dedication of the blades to one task would indicate that blades at Mound House were used expediently.

Table 1. Used Mound House Blades by Context

\begin{tabular}{lll}
\hline Blade type & Mound area & Habitation area \\
\hline Used blades & 25 & 31 \\
\hline Unused blades & 14 & 30 \\
\hline
\end{tabular}

Table 2. Total Site Use Wear by Material Worked

\begin{tabular}{lll}
\hline Use wear type & $\mathbf{n}=$ & Percentage \\
\hline Bone/antler & 8 & $16 \%$ \\
\hline Dry Hide & 5 & $9 \%$ \\
\hline Fresh Hide & 6 & $11 \%$ \\
\hline Meat & 19 & $35 \%$ \\
\hline Soft plant & 1 & $2 \%$ \\
\hline Stone & 1 & $2 \%$ \\
\hline Wood & 7 & $11 \%$ \\
\hline Unidentifiable & 9 & $14 \%$ \\
\hline
\end{tabular}

In addition to the identification of the material worked, the direction of use was also identified for the blades. Of the 56 with use-wear, 37 could have their motion of use identified. Striations were very rare in the sample overall, which seems to be the result of the blades generally not being utilized long enough for them to develop. Edge damage, the position of wear along the edge, and retouch were all considered when identifying the direction of use. All 19 blades with meat use-wear were identified as being used for butchery (Table 2). Five of the blades utilized on bone or antler had their motion of use identified. A retouched blade was used for scraping bone. One blade appears to have been made into a burin and used in an engraving motion. Three of the blades were used for sawing bone. All of the blades that were used for working dry hide had their motion identified. One of these was used in a scraping dry hide, while 
the other four were used in a cutting motion. Fresh hide proved more difficult in identifying the motion of use, although one was identified as being used in a scraping motion. The blade utilized for working stone was used in an engraving motion. Motion of use was identified for six out of seven of the blades used on wood. Four had been used in a sawing motion, while drilling and scraping account for the other two. The wear on the blade used on soft plant was not sufficiently developed to determine motion of wear, although it was likely used in a cutting motion.

Table 3. Blades With Motions of Use Identified

\begin{tabular}{lll}
\hline Motion & Material & $\mathbf{N}=$ \\
\hline Cutting & Meat & 19 \\
\hline Cutting & Dry Hide & 4 \\
\hline Drilling & Wood & 1 \\
\hline Engraving & Bone/Antler & 1 \\
\hline Incising & Stone & 1 \\
\hline Sawing & Bone & 3 \\
\hline Sawing & Wood & 4 \\
\hline Scraping & Wood & 1 \\
\hline Scraping & Bone & 1 \\
\hline Scraping & Dry Hide & 1 \\
\hline Scraping & Fresh Hide & 1 \\
\hline
\end{tabular}

Thirteen of the blades exhibited signs of retouching. Fortier's (2000) categories of retouched blade tools were used to classify the retouched Mound House blades. Four blades had retouching along a single edge for more than half of its length. These would be classified as a side scraper or perhaps as a knife. Two of these had use-wear classified as meat (Fig. 4E and 4G), while the other two (Fig. 4A and 4F) had no use wear present. One blade had uniform retouching on both edges and use-wear shows that it was used in a scraping motion on bone, classifying this as a scraper as well (Fig. 4L). Two blades had retouching in a single location to form a concave edge or weak notch. One of these had traces of meat use-wear (Fig. 4D) while 
the other's use wear was classified as unidentifiable (Fig. 4B). Two blades had retouching forming concavities in two or more places along the edge (Fig. 4J and 4M), which Fortier (2000) would classify as a denticulate. On the blade labeled Figure. $4 \mathrm{~J}$ one of these concavities has flakes taken off on the dorsal face, while the other two have flake scars on the ventral face. The other denticulate is retouched towards the dorsal face, as well as having the distal end of the blade retouched. Both denticulates have meat use-wear. One blade exhibits retouching on all edges, forming a tip on the proximal end (Fig. 4I). The heavy wear on this portion suggests it was used on wood, likely in a drilling motion. Another blade was retouched erratically around most of its edges (Fig. 4C), and was used on hide. One blade appears to have been notched for hafting (Fig. 4H), which use wear along the dorsal ridge near the notch confirms. Unlike the notches in Fortier's (2000) study, which are notched perpendicular to the long axis of the blade, the notch on this example extends diagonally into the piece towards the distal end. This hafted blade has use-wear along its edge suggested that it was used to cut meat. Another blade appears to have been used as a burin (Fig. 4J) for working bone. The platform of this blade and one of the edges forms a nearly right-angle, just like a burin, and is the area where the use-wear occurs. While the edge of the burinated section is squared off, it appears that the face of the core led to this, rather than modification after the blade was detached. All modified blades except for two (Fig. 4B and 4J) were from the habitation area. The vast majority of the blades were made from Burlington chert, both heat-treated and raw. Most of the blades that were not made from Burlington chert were made from the darker, extra-local Cobden-Dongola chert. Formal lithic sourcing was not part of this analysis. 


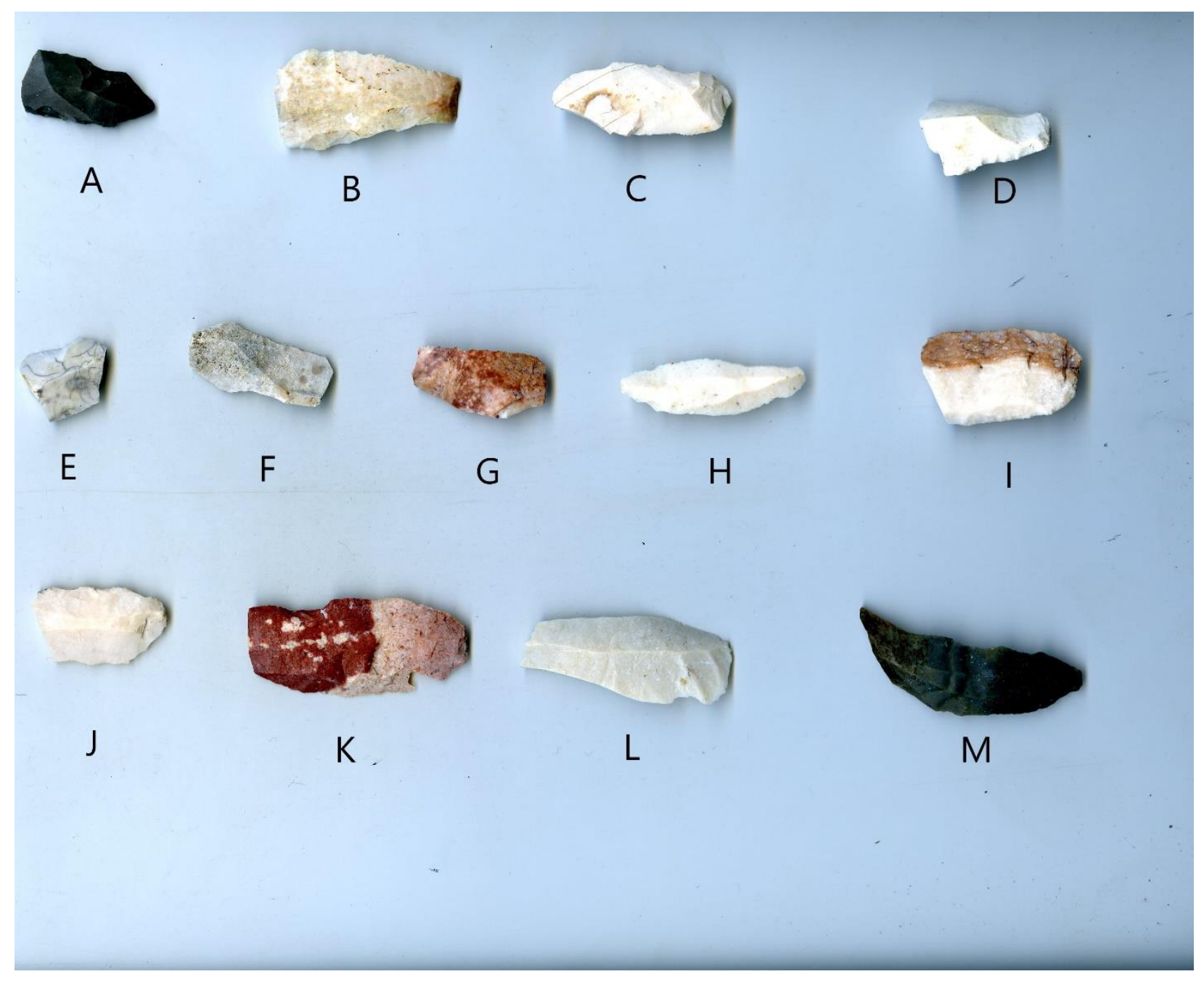

Figure 5. Blades with retouch or modification.

In order to understand patterns of use-wear across the site, blades were sampled from both the mound and habitation areas of the site. None of the blades sampled from the excavations of Mound 2 had use-wear present, although the number of blades from Mound 2 was far less than the number of blades from Mound 1. A total of 39 blades were sampled from the Mound 1 area, while 61 blades were sampled from the habitation and non-mound portions of the site. For the area around Mound 1, meat is still the most common category of use-wear present (Table 4). Bone/antler use wear is the second most common type of wear present, although wood is nearly as well represented. Dry hide and fresh hide use-wear are also minimally present in this area, 
along with the one of instance of soft plant working. Eight blades in the mound sample were from the squares containing the concentric postmolds beneath Mound 1, which is thought to be a ritual screen. Of these 8 blades, 3 had use-wear, which were identified as meat wear, wood wear, and dry hide wear.

Table 4. Mound Area Use Wear.

\begin{tabular}{lll}
\hline Use wear type & $\mathbf{n}=$ & Percentage \\
\hline Bone/antler & 4 & $18 \%$ \\
\hline Dry Hide & 2 & $9 \%$ \\
\hline Fresh Hide & 1 & $4 \%$ \\
\hline Meat & 11 & $48 \%$ \\
\hline Soft plant & 1 & $4 \%$ \\
\hline Stone & 0 & $0 \%$ \\
\hline Wood & 4 & $17 \%$ \\
\hline
\end{tabular}

Within the habitation area, meat use-wear is the largest category of wear, although it is less abundant here than in the mound area (Table 5). Fresh hide is the second most abundant type of wear in this area. Dry hide is also well represented in the habitation area. Bone is equally frequent in both areas. Wood use wear is slightly less frequent in the habitation area than in the Mound area. Finally, the only instance of stone use-wear occurs in this area of the site.

Table 5. Habitation Area Use Wear

\begin{tabular}{lll}
\hline Use wear type & $\mathbf{n}=$ & Percentage \\
\hline Bone/antler & 4 & $17 \%$ \\
\hline Dry Hide & 3 & $12 \%$ \\
\hline Fresh Hide & 5 & $21 \%$ \\
\hline Meat & 8 & $33 \%$ \\
\hline Soft plant & 0 & $0 \%$ \\
\hline Stone & 1 & $4 \%$ \\
\hline Wood & 3 & $13 \%$ \\
\hline
\end{tabular}




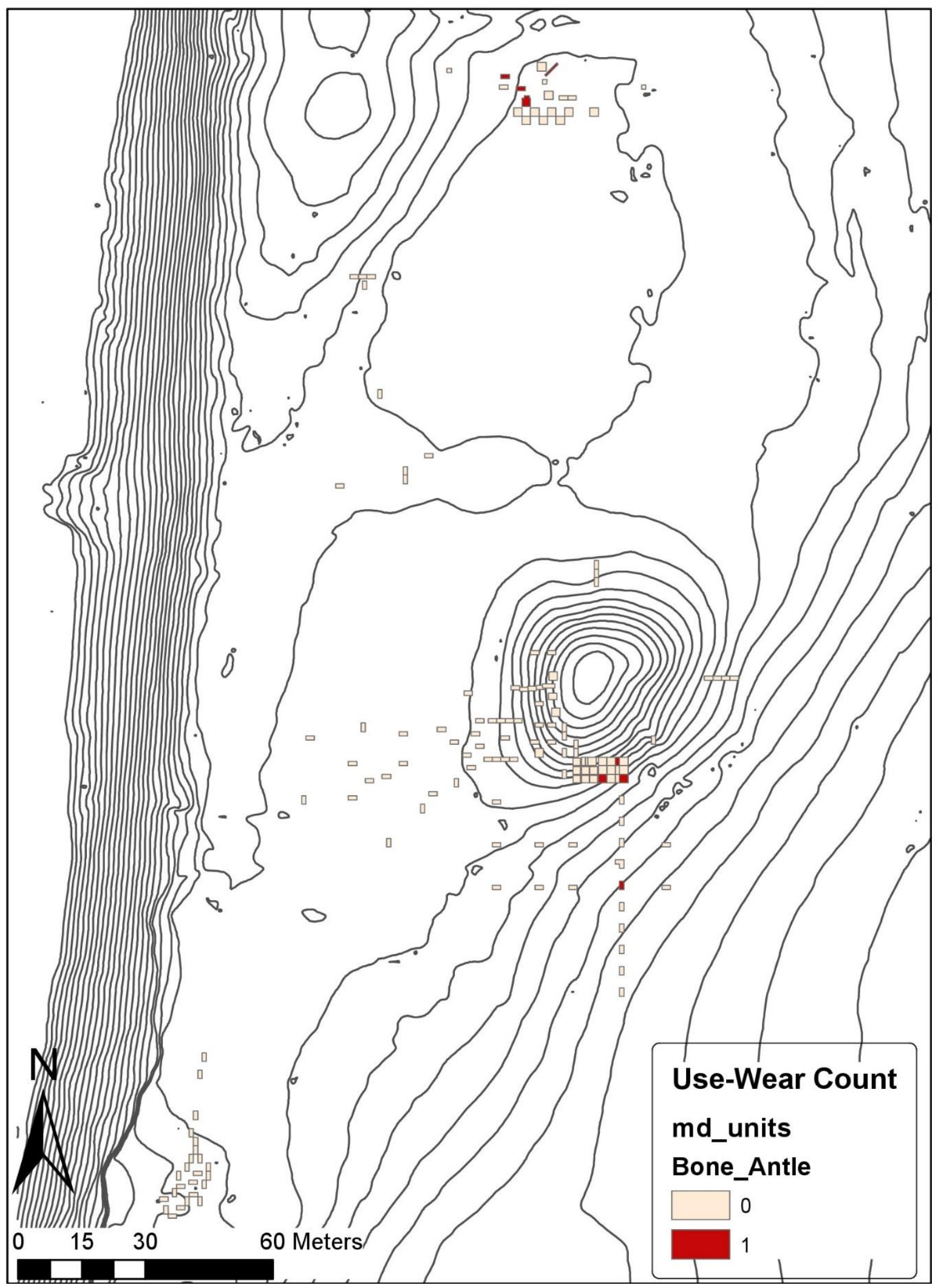

Figure 6. Bone and Antler Use-Wear Distribution at Mound House. 


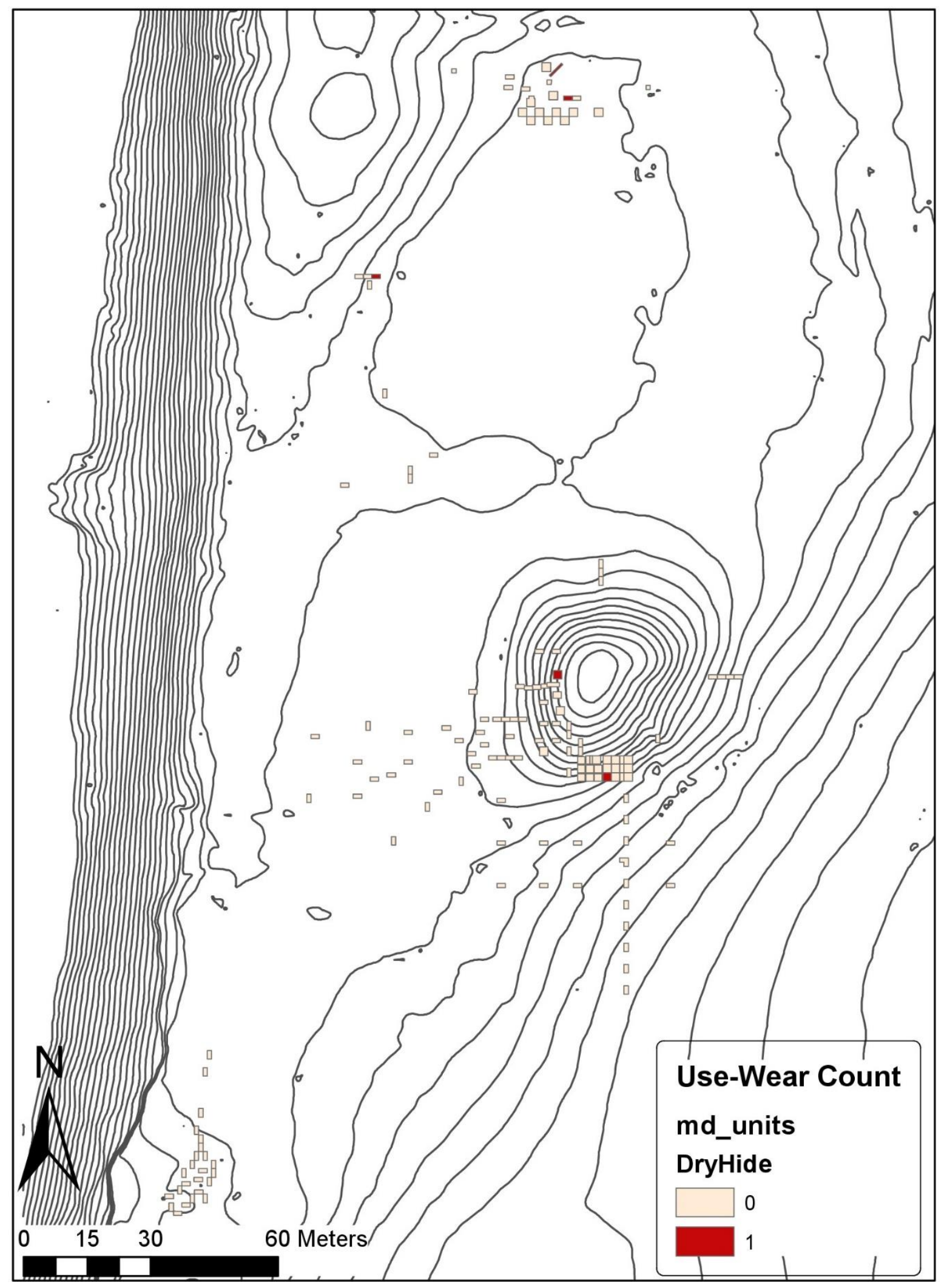

Figure 7. Dry Hide Use-Wear Distribution at Mound House. 


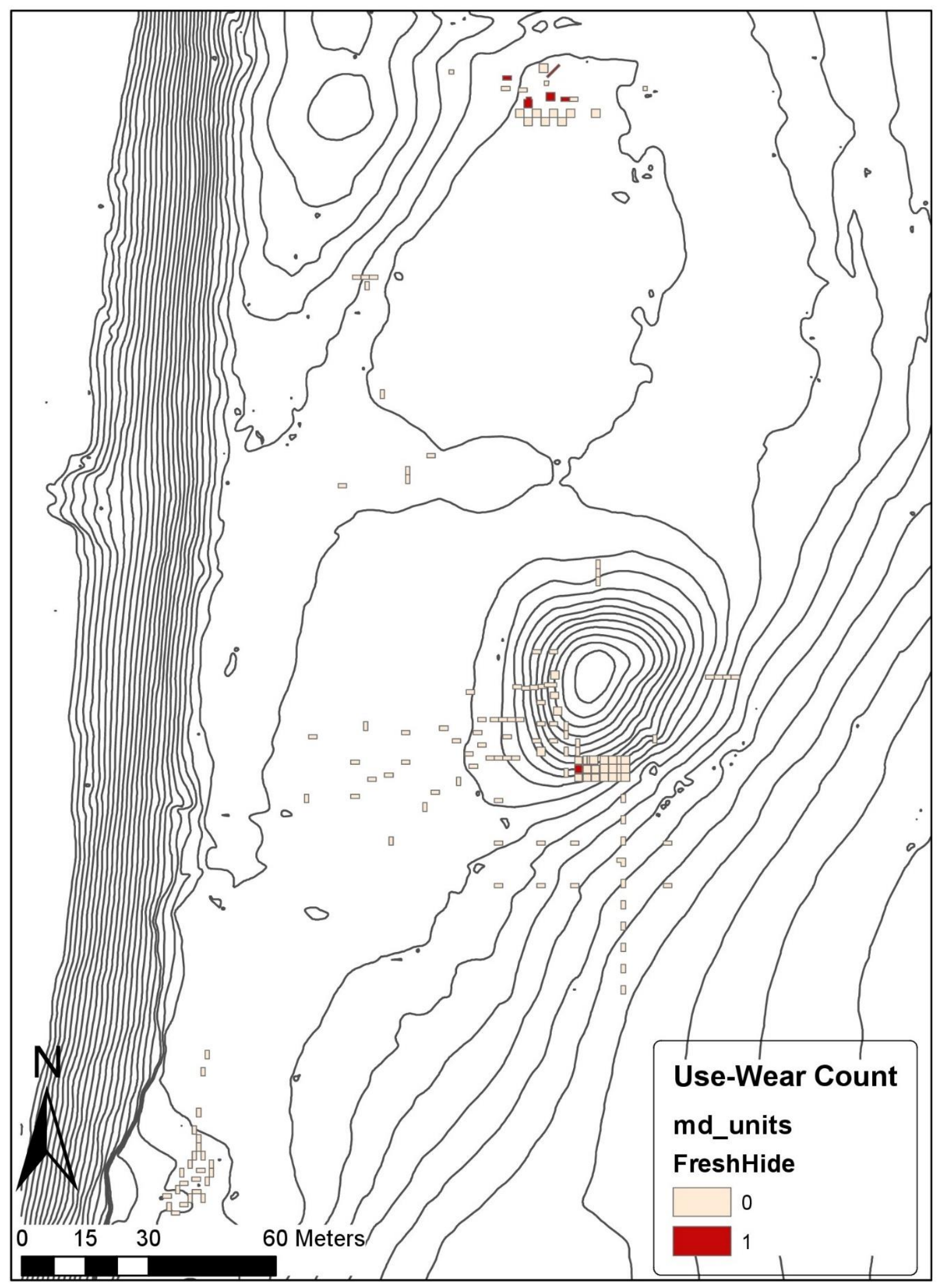

Figure 8. Fresh Hide Use-Wear Distribution at Mound House. 


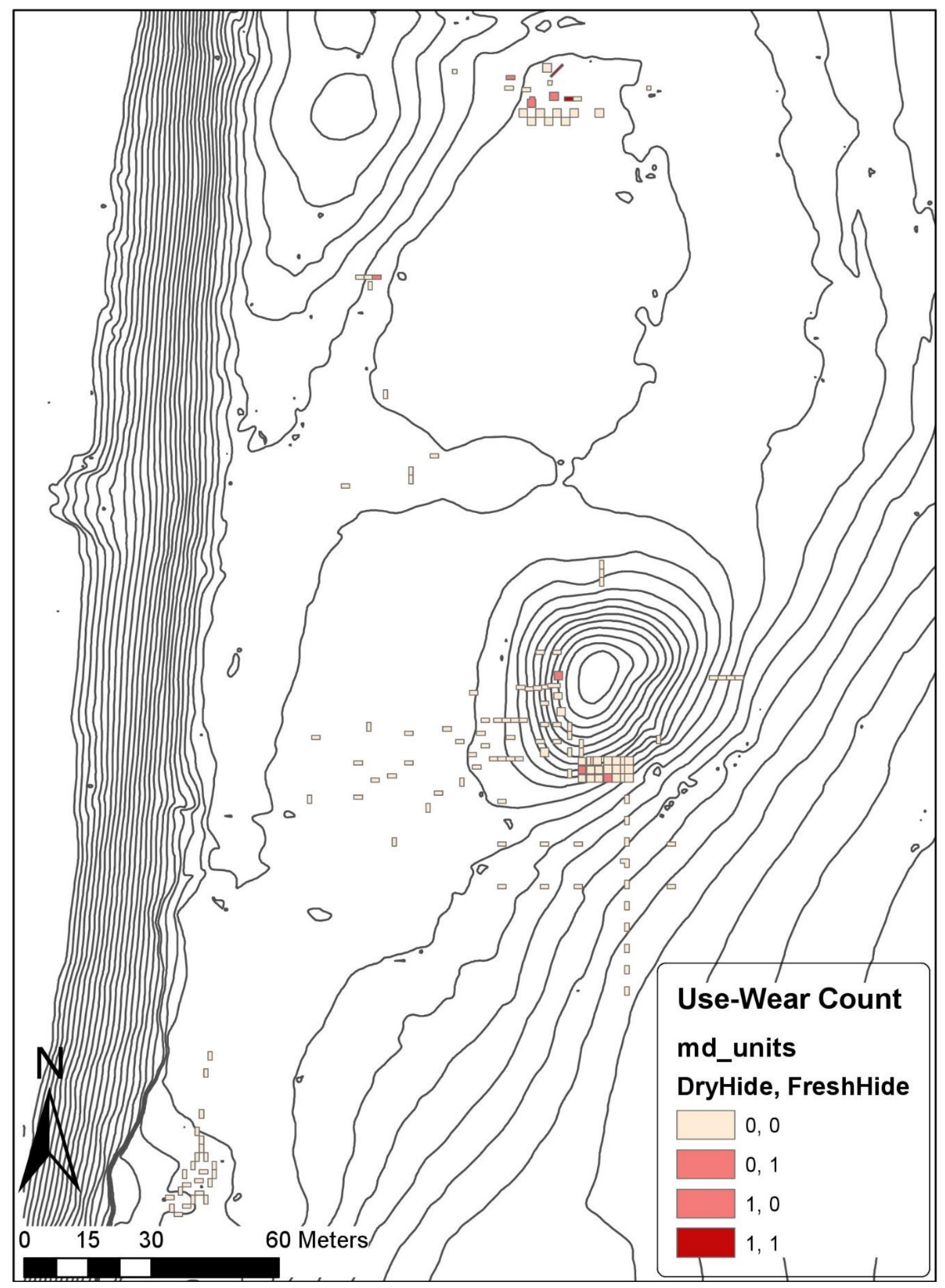

Figure 9. Dry Hide and Fresh Hide Combined Use-Wear Distribution at Mound House. 


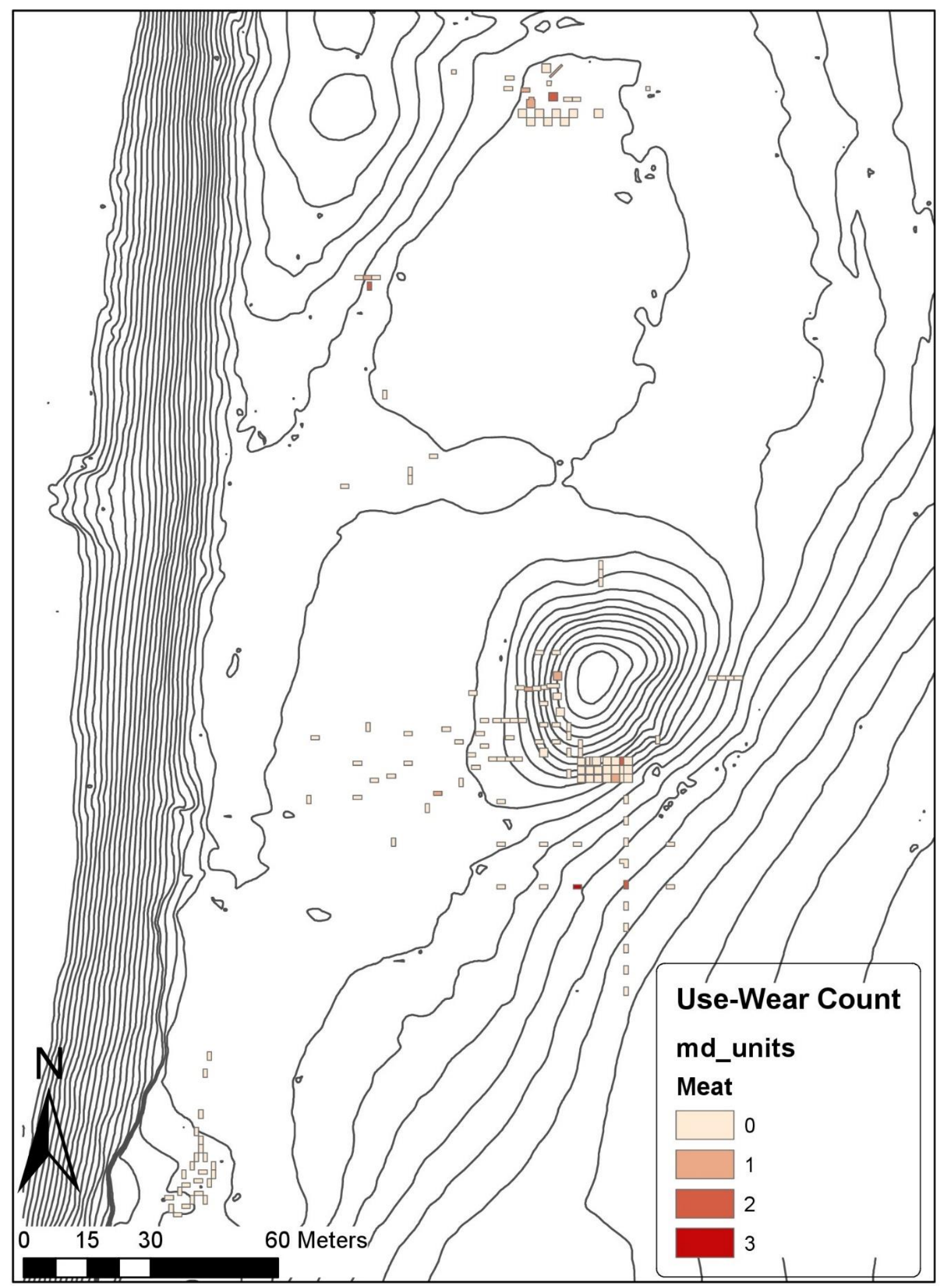

Figure 10. Meat Use-Wear Distribution at Mound House. 


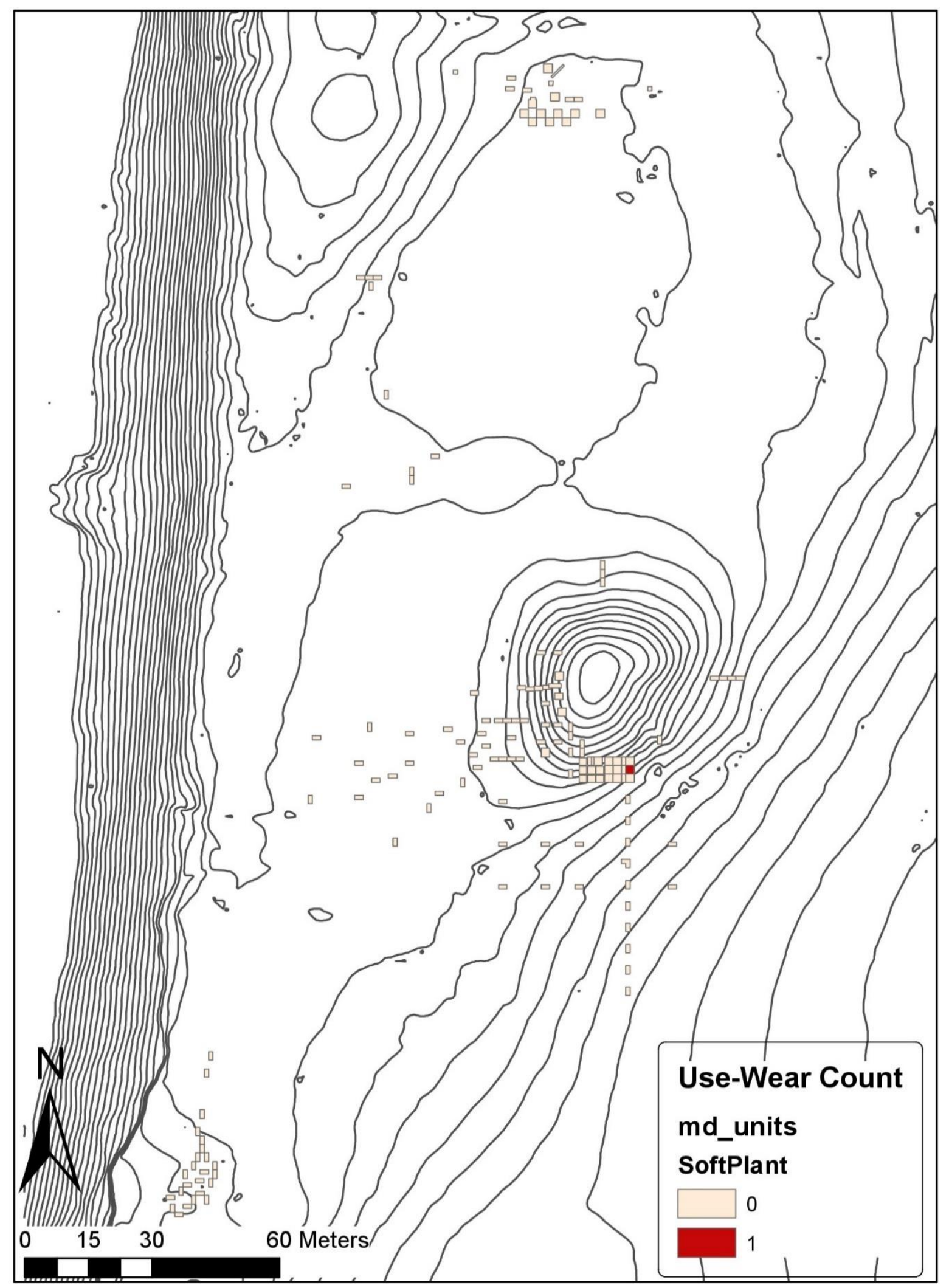

Figure 11. Soft Plant Use-Wear Distribution at Mound House. 


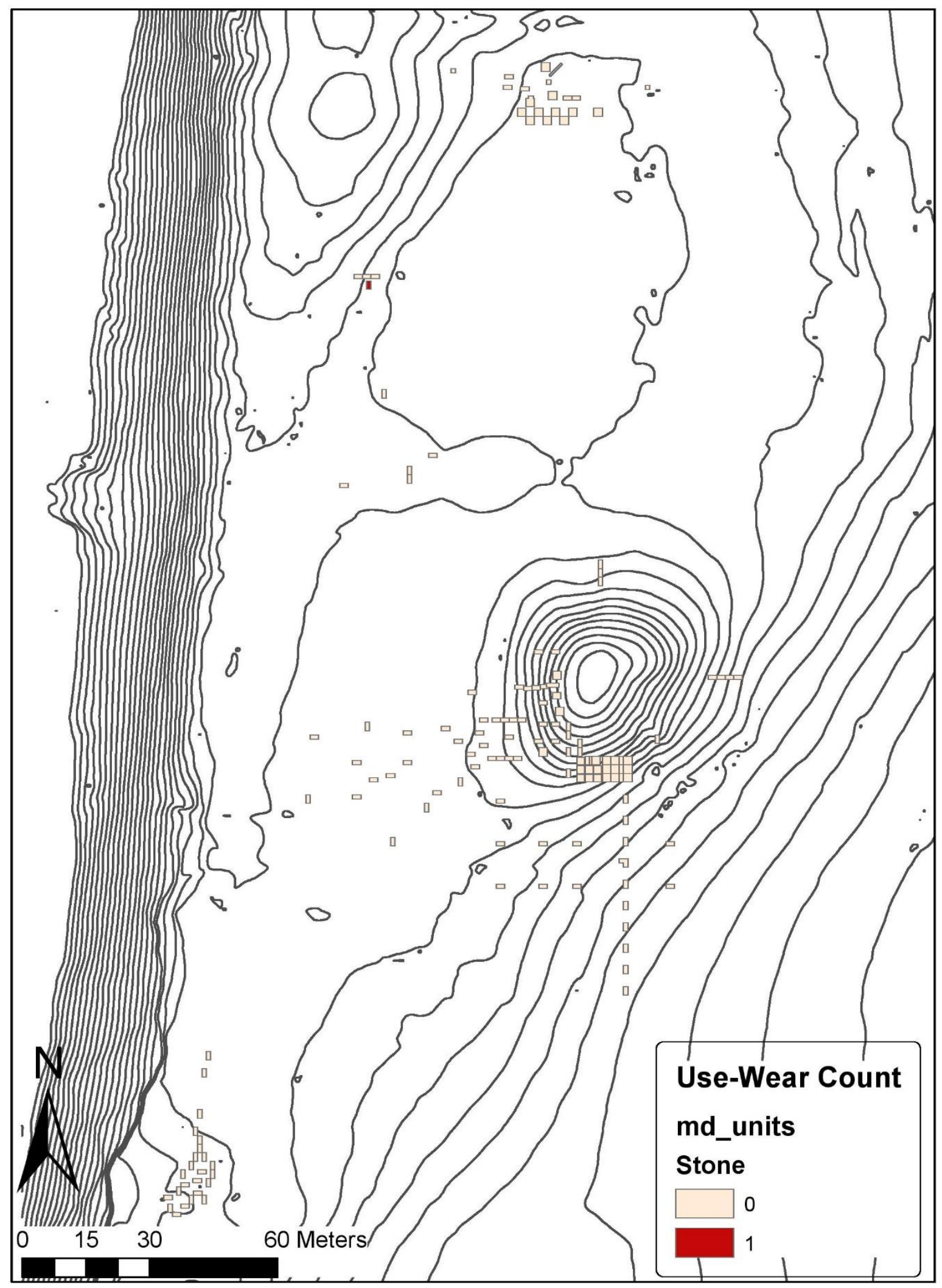

Figure 12. Stone Use-Wear Distribution at Mound House. 


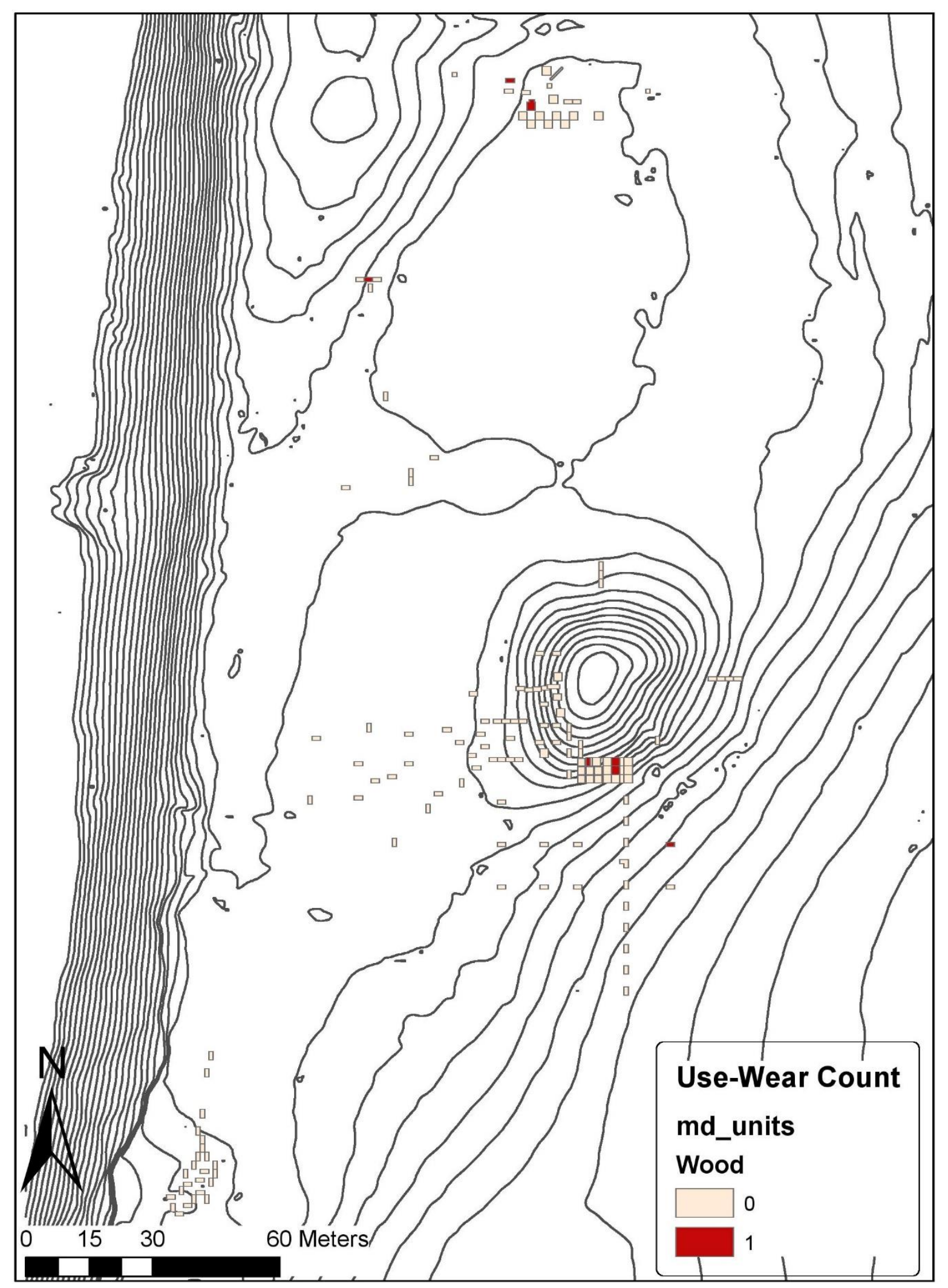

Figure 13. Wood Use-Wear Distribution at Mound House. 
A total of 44 blades in the sample were unutilized. The degree of completeness was recorded for every blade. This helps determine if unutilized blades were defective and as such discarded, or if the were mostly whole and set aside for later use. In terms of blades that were utilized, knowing their completeness helps us understand if they were discarded because of breakages. Blades were put into three different categories depending on completeness. Blades that were nearly entirely complete were classed as "complete". Blades that had been broken yet still met the technical requirements of a blade (2-3x longer than wide) and were still usable as tools were classified as "broken". Blades that had been broken so that they did not meet the technical requirements of a blade and/or were too small to function as tools were classified as "fragments". Table. 6 illustrates the difference in completeness between the utilized and unutilized blades in the Mound House sample. While an equal number of complete blades were unused and used, a greater proportion of the unused were complete compared to the proportion of used complete blades. A greater number and proportion of utilized blades were broken and fragmented. In fact, when looking at the proportions of the utilized blades, they are fairly equal for each category of completeness. Unutilized blades have the greatest percentage of complete blades, with less that were broken and even less fragmented. Using Fisher's exact test, the distribution of utilized vs. unutilized blade completeness was examined. The p-value generated $(p$-value $=0.6491)$ does not suggest that there is a statistically significant difference between these two categories.

Table 6. Degree of Completeness for Blades, Unused vs Used

\begin{tabular}{lllllll}
\hline Blade Type & $\begin{array}{l}\text { Complete } \\
(\mathbf{N}=)\end{array}$ & $\begin{array}{l}\text { Broken } \\
(\mathbf{n}=)\end{array}$ & $\begin{array}{l}\text { Fragment } \\
(\mathbf{N}=)\end{array}$ & $\begin{array}{l}\text { Complete } \\
(\boldsymbol{\%})\end{array}$ & $\begin{array}{l}\text { Broken } \\
(\boldsymbol{\%})\end{array}$ & $\begin{array}{l}\text { Fragment } \\
(\boldsymbol{\%})\end{array}$ \\
\hline Unutilized & 18 & 15 & 11 & $41 \%$ & $34 \%$ & $25 \%$ \\
\hline Utilized & 18 & 20 & 18 & $32 \%$ & $36 \%$ & $32 \%$ \\
\hline
\end{tabular}




\section{CHAPTER VI: DISCUSSION}

Tracing use-wear patterns to specific activities, either fabricating or extractive, can be challenging as some types of wear can produce objects in either category. Stone and shell usewear can be most likely linked to producing Hopewell craft, ritual, and exchange items. The results from Mound House show only one instance of stone engraving/incising and no evidence for working shell. Mica is often cited as an important Hopewell craft material, and blades are often attributed to the production of mica items (Miller 2015; Yerkes 1994). While mica is present in limited quantities at Mound House, the one instance of stone use-wear at the site is not consistent with what would be seen from cutting mica sheets. It was likely used for incising pipestone, slate, hematite, or another kind of harder stone employed in crafts other than mica.

Bone and antler wear can be the result of a number of activities relating to subsistence or craft production. Producing flintknapping tools, fishhooks, awls, pins, needles, etc. are all utilitarian objects that when produced, would leave use-wear on any sort of blade used to create them. Effigy figures, gorgets, bear teeth, and flutes are all bone items that have been found in Hopewell contexts that relate to ritual function (Miller 2015). Turtle-shell rattles are well known to be part of Native American ceremonial practices (Brown and Peres 2017), which due to being made of bony material, would likely result in use-wear very similar to bone or antler. Turtle shell fragments were recorded as being present in some of the units from the Mound 1 excavations, although poor preservation of faunal materials at the site did not allow for any possibility of cultural modification being preserved (Buikstra et al. 1995). The determination of tool motion can greatly assist in distinguishing bone wear from utilitarian tasks from those involved in producing Hopewell craft items. Materials like bone and antler, dry hide, and wood can be used in utilitarian or craft objects. Miller (2015) states that motions of engraving, drilling, and 
perforating these materials is used for the production of craft objects. A single blade from Mound House, from post-mold 302, had wear indicating it was used with an engraving motion on bone or antler. This use wear occurs at the proximal end of the blade, where a previous flake scar naturally produced a burin like edge.

Wooden objects were certainly produced by Middle Woodland people for utilitarian needs, but due to the perishable nature of plant materials, it is unknown how commonly wooden materials were used to produce Hopewellian crafts. Most of the use-wear related to wood working at Mound House seems to have been employed in sawing, although one blades appears to have been retouched and used extensively as a drill on wood. Leather items provide a similar problem, because in most cases they are not preserved. In one exceptional case, a number of well-preserved, ritual leather items were found in the excavations at the Mount Vernon site (Tomak 1994). Working both fresh and dry hide would have been part of the process to make leather, and ultimately, clothing. Clothing can be made for daily use or could have been fashioned into special ceremonial garbs. There does not appear to be any signs of the blades at Mound House used for perforating dry hide, which would indicate the production of ceremonial garbs (Miller 2015). Meat use-wear obviously relates to butchering activity so that it can be consumed. Other use-wear studies of Hopewell blade use-wear have demonstrated that meat usewear is very common across different kinds of sites (Lemons and Church 1998; Miller 2015; 2018; Odell 1994; Yerkes 1994). Within the context of the Mound House site, the dominance of meat-related activity is probably related to feasting that occurred at the site. 


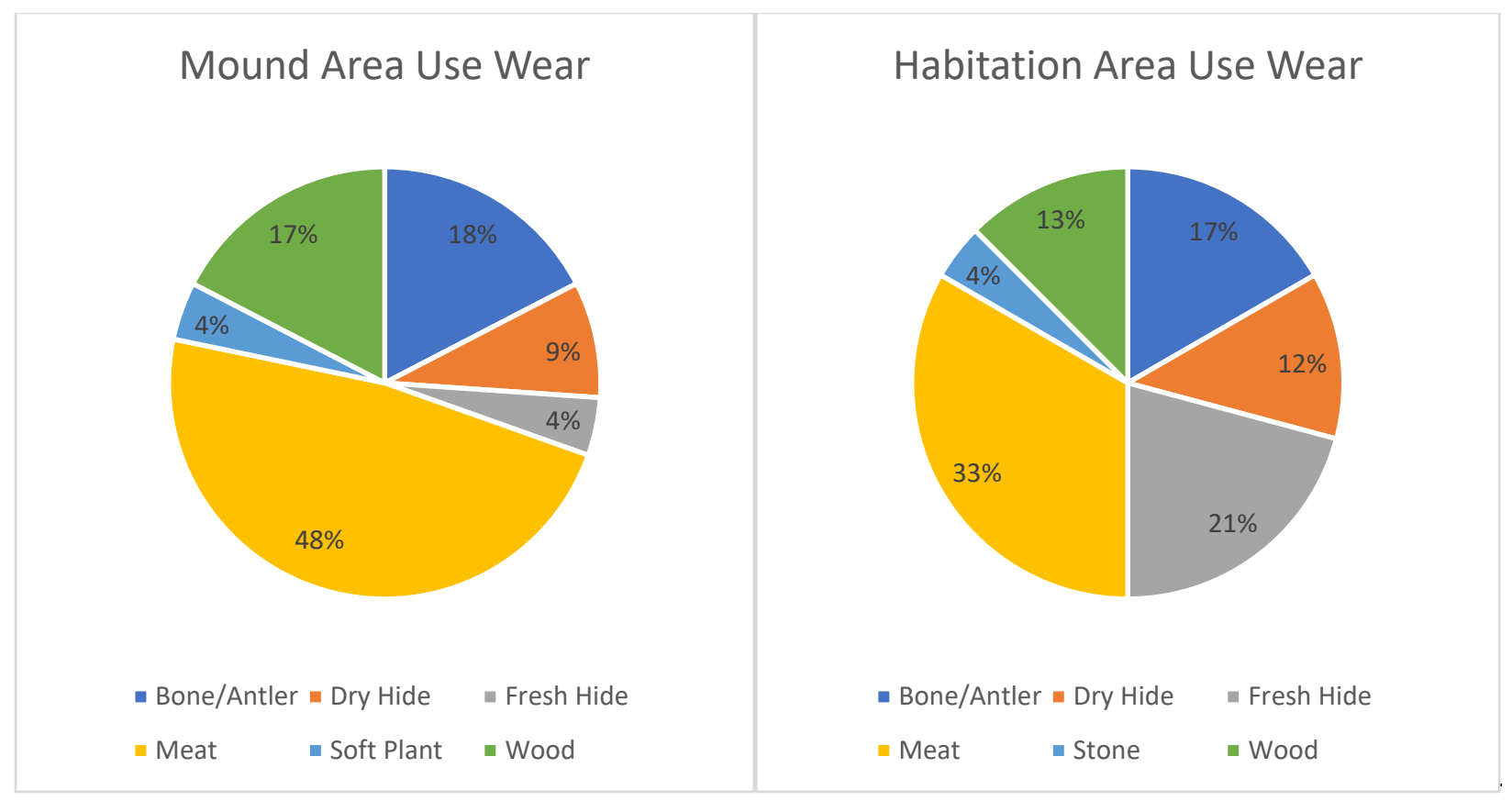

Figure 14. A comparison of use-wear distributions in the different Mound House contexts.

The distribution of use-wear types varies over the mound and habitation areas of the site. The habitation area has the greatest concentration of unused blades $(n=30)$, with a nearly equal proportion of used and unused blades $(n=31)$ (Table 1). Unused blades are much less common in the mound area $(n=14)$, while used blades $(n=25)$ are only slightly less common here than in the habitation area. According to Morrow (1989) there seems to be a concentration of blade production activity north of Mound 1 and in the open space between Mounds 1 and 2. Morrow argues this based not only on the sheer number of blades present, but also the relatively high number of blade cores in relation to the number of blades. The number of unused blades and high proportion of complete blades (Table 1) in this area would seem to support this idea. Evidently, blade production was an important activity in the habitation area of Mound House.

Meat use-wear is the dominant category of wear in both areas (Fig. 13), although it is more frequent in the mound area. This wear seems to be the result of butchering and cutting flesh. Both fresh and dry hide working are more common in the habitation area of the site than 
mound area. The same number of blades with bone/antler use wear were present in both areas of Mound House. Wood use wear was also similarly represented proportionally in the habitation and mound contexts. The proportion of blades used for hide working in the habitation area (33\%) compared to the mound area $(13 \%)$ is the most conspicuous pattern between the two areas. There may have been a reason for the people at Mound House to prefer to do hide working activities away from the mound area. While hide working seems to have been present in both areas, there does seems to a greater concentration of these activities in the habitation area, especially with fresh hide working. This pattern is interesting, especially considering that fresh hide working is a much dirtier activity, which may not have been as welcomed in the mound area. This is not to say that the mound area was necessarily a "sacred space" in which certain activities were forbidden, but that just other types of activities were conducted here than those in the habitation area. It can be difficult to distinguish between utilitarian and special activities based on use wear. Determining the motion of use can help distinguish what a blade was used for, although due the light use-wear on most of the blades this was difficult to determine. Some activities can be the result of either utilitarian or special tasks depending on context, such as cutting meat or hide and carving wood. The widespread and dominance of meat use-wear across the site is unsurprising. For floodplain mound centers, feasting was almost certainly one of the important activities that took place to bring the Middle Woodland communities together. The greater proportion of meat use-wear in the Mound 1 than in the habitation area attests to the importance of feasting in rituals in this area of the site. In order to compare the two areas, Fisher's exact test was conducted to see if there was significant difference between the use-wear on the assemblages in the mound and habitation area contexts. The results were not significant ( $\mathrm{p}$-value $=0.5384$ ). That is not to say 
that there is not a difference between the two areas of Mound House, but not one that's statistically relevant based on the sample size present in the mound and habitation areas.

The proportion of retouch is something that also differed between the two areas of Mound House. Eleven of the thirteen blades that were retouched into formal tools were from the habitation area. The two blades with retouching that are from the mound area include the bone/antler working burin (Fig. 4L) and a blade with a concave retouched area (Fig. 4C). This pattern suggests that blades in the habitation area were more likely to be curated and modified into tools. In light of the idea that people at Mound House were probably spending more time in the habitation area than the mound area when not participating in ceremonies, this distribution makes sense. Blades with retouching, modification, and notching tend to be more common at Illinois Middle Woodland sites than at Ohio sites. At other Middle Woodland sites in the Southeast, such as those examined by Kay and Mainfort (2014) and Kimball (1992), blades also seem to be commonly modified. However, at these sites blades seem to have been modified into burins and engraving tools through intentional snapping. The Mound House assemblage has a single blade which appears to have been a burin, although it appears that whoever utilized it may have taken advantage of the angles of the piece, and may not have even modified it.

In order to more completely understand the microwear data from Mound House, it should be compared to other sites where microwear on Hopewell blades has been analyzed. The studies examined here come from a variety of different Middle Woodland sites. None of these sites are Illinois Middle Woodland floodplain mounds, meaning that the sites aren't completely similar. Comparing Mound House to these sites is still useful in order to understand how Hopewell blade use functioned in various contexts. Other Illinois floodplain mound groups would be expected to have similar distributions of use-wear in their blade assemblages. Sites of this category were 
used for similar contexts by communities of Middle Woodland people for bringing together a symbolic community and the types of activities in these contexts would result in the blades that were utilized to have similar kinds of wear. If we are to use the different types of Illinois Middle Woodland sites presented by Ruby and others (2005), we would expect to see a variety of different activities. Habitation sites would have high proportions of use-wear relating to subsistence activities. However, these hamlets would also have use-wear resulting from long term craft projects (Odell 1994) that were prepared here and brought to other kinds of sites, such as bluff-top and floodplain mounds. Wear resulting from craft projects would be expected from both blufftop mounds (see Odell 1994) and floodplain mounds in lesser amounts, since people would not being staying long enough at these sites to complete major craft projects for use in ceremonies or to be interred with burials. This idea is reinforced by the amount of wear in the Mound House assemblage relating to craft production. Wear resulting from mortuary activities would be expected from bluff-top mounds groups (Odell 1994) as these functioned as community cemeteries (Ruby et al. 2005). Since large floodplain mound groups contained less burials, we would not expect to see much evidence of mortuary preparation. Both habitation and floodplain mound groups would have use-wear related to butchery. Since we know that only a few families occupied hamlets, this butchery would relate to daily meal preparation. Because there is a lack of evidence that floodplain sites were occupied for significant amounts of time, this is not the case for Mound House. Instead the butchery wear can be interpreted as being produced by feasting from large number of people who came to the site for a short period of time.

The Murphy Site was examined by Yerkes in a 1994 study. Murphy, unlike Mound House, is a habitation site. Quite a few blades were analyzed for this study, totaling to 231 blades 
with 43 showing signs of use-wear. However, both Murphy and Mound House have very similar distributions of meat cutting use-wear (Fig. 14). Both sites also have similar proportions of bone/antler working and wood. The entire Mound House blade assemblage does have significantly more hide working use wear (20\% vs. $8 \%$ ) than the Murphy site. Stone working with blades does seem to have been more common at Murphy. If you compare the meat processing proportions of the Mound House habitation area the Murphy site assemblage, they have the same proportions of wear. Comparing the mound area in the same manner shows that this site portion has a higher percentage of meat processing use-wear than Murphy (Fig. 13 \& 14). The habitation area has the same proportion of wood-working wear to the Murphy site, although in the mound area of Mound House there is a greater proportion of wood-working wear (Fig. 13 \& 14).

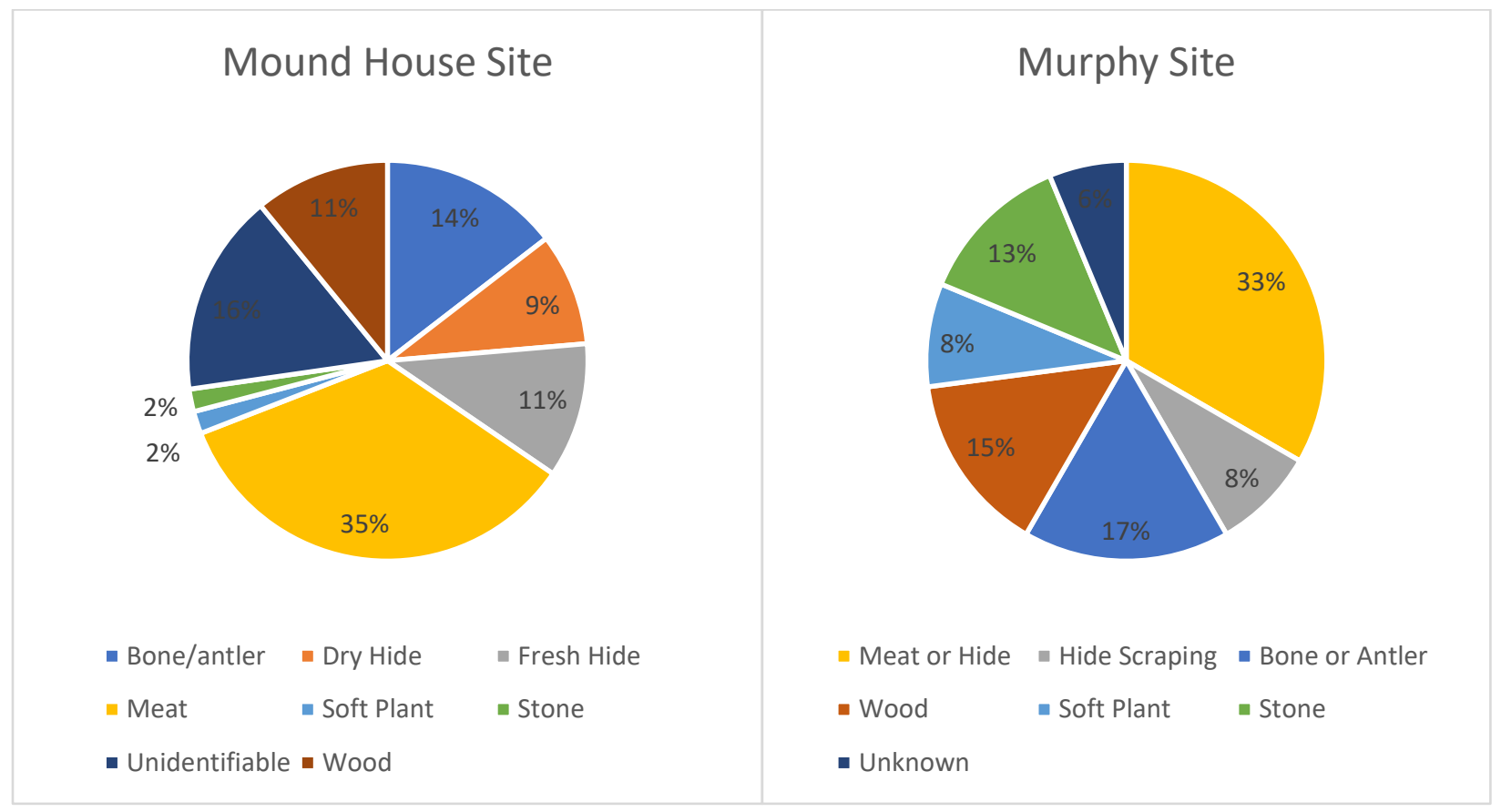

Figure 15. A comparison of the Mound House site and the Murphy site use-wear assemblages. 
Miller (2018) examined two sites associated with the Stubbs Earthworks in Ohio, the Smith Site and Circle Overlook. Here, I only compare the Mound House assemblage to the Smith site, since Circle Overlook has a rather small number of blades with use-wear $(n=8)$. A total of 113 blades from the Smith site were analyzed, and 44 of these showed signs of use. Usewear related to meat butchery is far more common at Mound House than at Smith, nearly double in terms of proportions (Fig. 15). Bone/antler use wear seems to have been far more important at Smith than at Mound House and is the largest category of wear at the site. Miller suggests that this means the production of bone/antler symbolic craft objects at Stubbs Earthworks was the primary activity at the site for the utilization of blades. Notably, use-wear from slicing soft plants only occurs on one blade at Mound House, while at Smith it makes up a significant portion of the use-wear. Wood use-wear is much more common at Mound House than at Smith, where it is only represented on a singular blade. Hide working activities are important parts of both assemblages, although a greater proportion does occur in the Smith site assemblage.

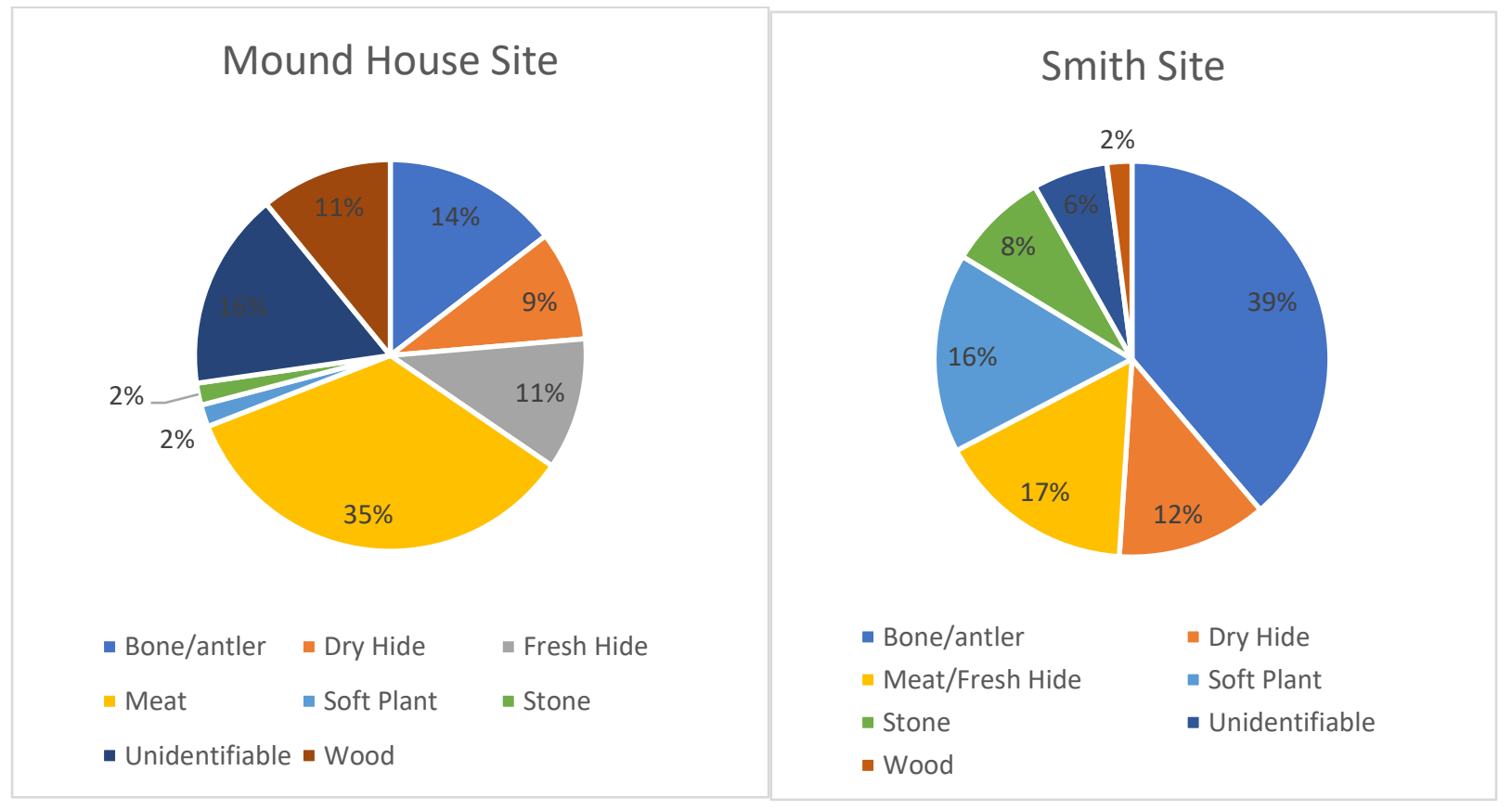

Figure 16. A comparison of the Mound House site and the Smith site use-wear assemblages 
Due to how Lemons and Church (1998) classify categories of material worked, it is hard to make direct comparisons from their study to the Mound House assemblage. It is not fully explained in their data why there are repeated categories (such as hide/meat and meat hide), or if these categories represent something different, what it means. It appears that at least some of these represent blades with multiple types of wear, although this does not adequately explain the repeated categories. Despite this, general comparisons can be made to Mound House. A relatively small number of blades were in this sample, 36, and 17 had use-wear. At Paint Creek Lake Site \#5, bone use-wear (Fig 16) seems to be as frequent there as at Mound House. Soft plant working activities, however, are completely absent, as well as stone working. The low instances of wood working at Paint Creek Lake contrasts with the findings at Mound House, where it makes up a notable part of the assemblage. Hide working wear makes up a fifth of the wear at Mound House, while at Paint Creek Lake it is present on over half of the blades. Similar amounts of meat microwear at present at both sites. While the Paint Creek Lake Site \#5 does lack soft plant and stone use-wear in its assemblage, a minor amount of shell working is present here, which is absent at Mound House. 


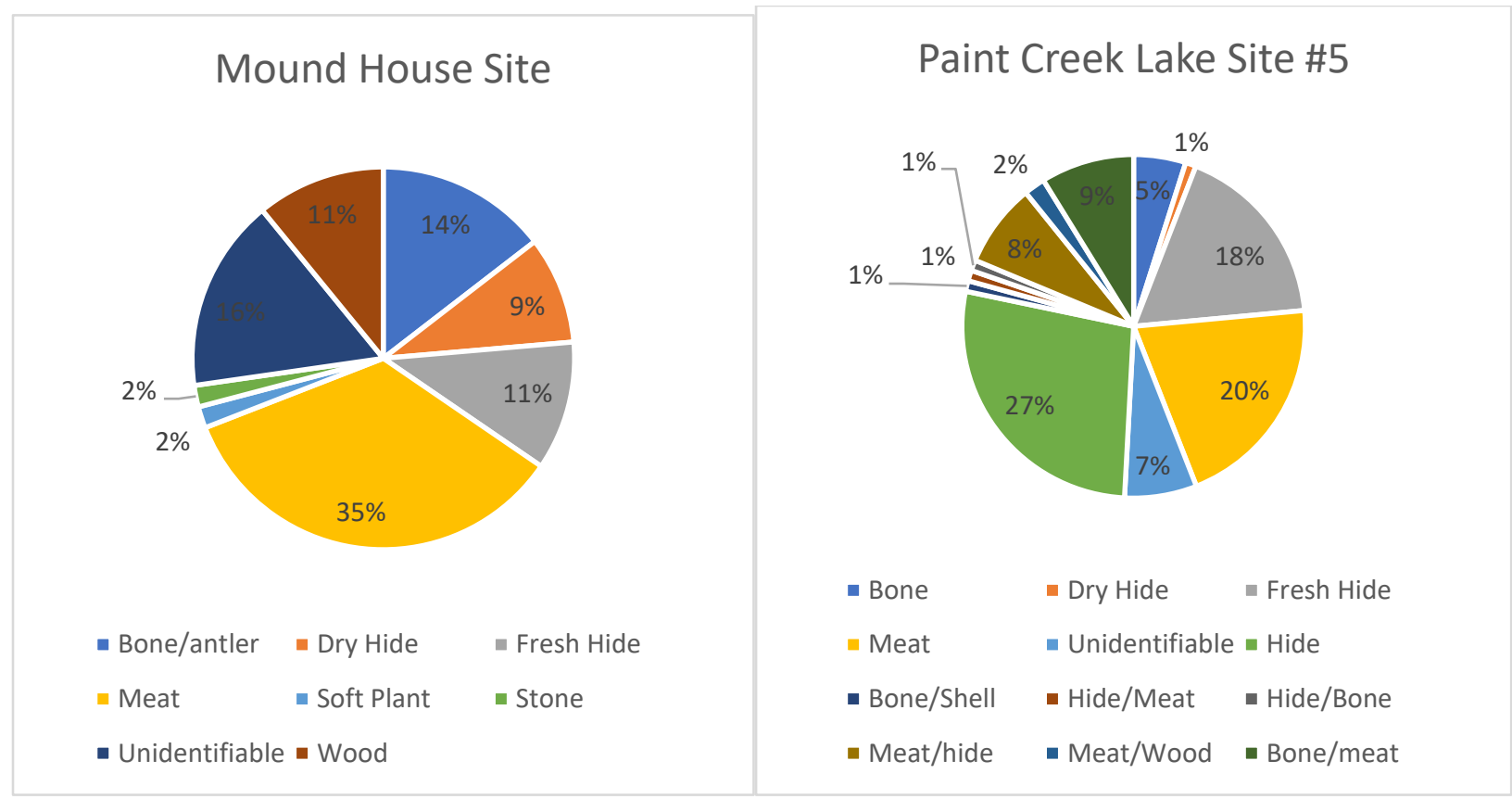

Figure 17. A comparison of the Mound House site and the Paint Creek Lake Site \#5 use-wear assemblages.

Miller's 2015 microwear analysis at the Ft. Ancient earthworks site in Ohio looks at blades from seven different contexts at the site. The types of wear and proportions were all done individually, and there was no summary of use-wear for the entire site, which is likely due to its size. As such, the Mound House assemblage will be compared to all of these contexts. One notable difference between the way Miller (2015) classifies use-wear and the way the Mound House blades were classified is that Miller put meat and fresh hide use-wear in the same category. Since the two are very similar, it is easy to see why this choice was made, just like how antler and bone are often lumped together. The total Ft. Ancient sample consists of a staggering 762 blades. The first context from Ft. Ancient in this comparison is the North Fort Gateways, which served as gateways or entrances to the earthworks. Comparing the Mound House data to the North Fort Gateways (Fig. 17) shows that in both contexts, meat use-wear has the same frequency. Bone/antler microwear has very similar frequencies in both contexts as well. The most notable difference is in the proportions of stone and plant use-wear. While these types of 
wear are infrequent at Mound House, they are well represented in the North Fort Gateways. Comparing the Mound House blades to those in Lots 17 and 18 (Fig. 18), which are located outside the earthworks, we see that meat use-wear is much more frequent in the latter context. Twin Mounds, also located outside of the main enclosure, (Fig. 19) shares a similar, though slightly less frequent, amount of meat use-wear to the Mound House assemblage. What is notably different compared to Mound House here is that soft plant use-wear has a high frequency $(32 \%)$. However, the proportions of stone, bone/antler, wood, and dry hide use-wear have similar frequencies in both of these contexts. Twin Mounds also has shell use-wear present in its blade assemblage, although it only makes up a small part. Comparing the Interior Household Cluster (which is inside the enclosure area) of Ft. Ancient to Mound House, the latter has more meat usewear in comparison to the former (Fig. 20). Stone use-wear on blades has a high frequency in the Interior Household Cluster. Other categories of use-wear in these contexts are fairly comparable. Moorehead Circle (also inside the earthworks) (Fig. 21) has a higher frequency of dry hide usewear and has shell use-wear present, while the other categories have similar frequencies to the Mound House assemblage. Waterline Trench Six (Another location inside the earthen enclosure) only has four different categories of wear present (Fig. 22), although this partly reflects the low number of blades recovered and analyzed in this context. What is notable is the high percentage of stone use-wear in this area, a use-wear category that is not well represented at Mound House. The Middle Fort (Fig. 23), located near the gateways/entrances, also has a low number of blades in it. However, meat use-wear has similar frequencies in the Middle Fort and Mound House contexts. The former has more bone/antler and stone wear. Broad comparisons of the Ft. Ancient and Mound House sites reveals several things. Craft production seems to have been more important at Ft. Ancient, as stone use-wear is more frequent in every context than in the Mound 
House assemblage. Bone/antler use-wear is as frequent or more frequent in the Ft. Ancient contexts compared to the Mound House site, as is dry hide use-wear. Shell use-wear is not present at Mound House, and though only present in minor frequencies at Ft. Ancient, is another sign of Hopewell craft production. Soft plant use-wear is more frequent at Ft. Ancient, which Miller (2015) suggests is the result of the production of plant fiber objects. The frequency of usewear relating to Hopewell craft production at Ft. Ancient is unsurprising due to the greater number of these kinds of artifacts at the site when compared to the relatively low numbers at the Mound House site (Buikstra et al. 1998).

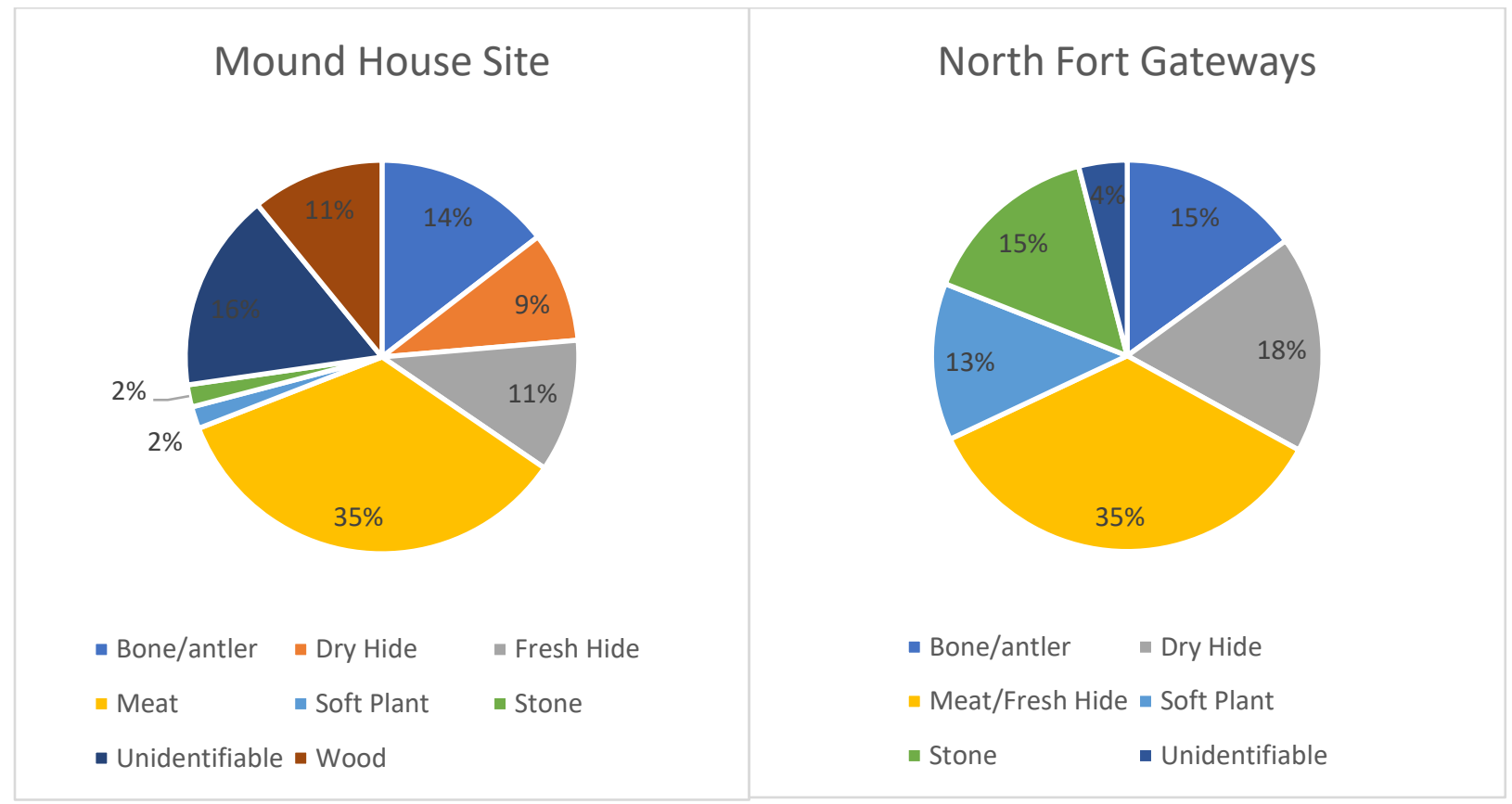

Figure 18. A comparison of the Mound House site and the Ft. Ancient site assemblage in the North Fort Gateways. 


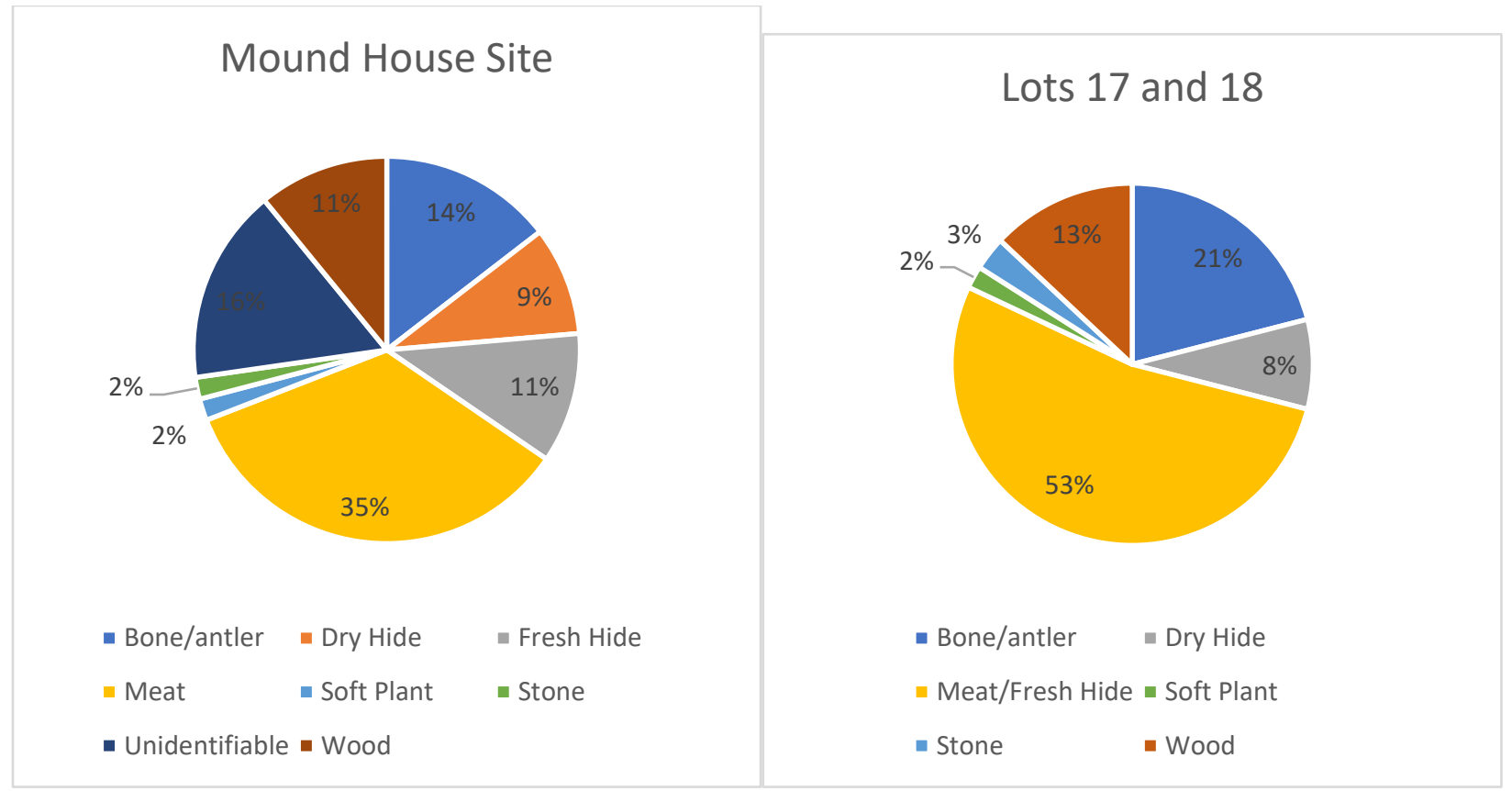

Figure 19. A comparison of the Mound House site and the Ft. Ancient site assemblage in Lots 17 and 18.
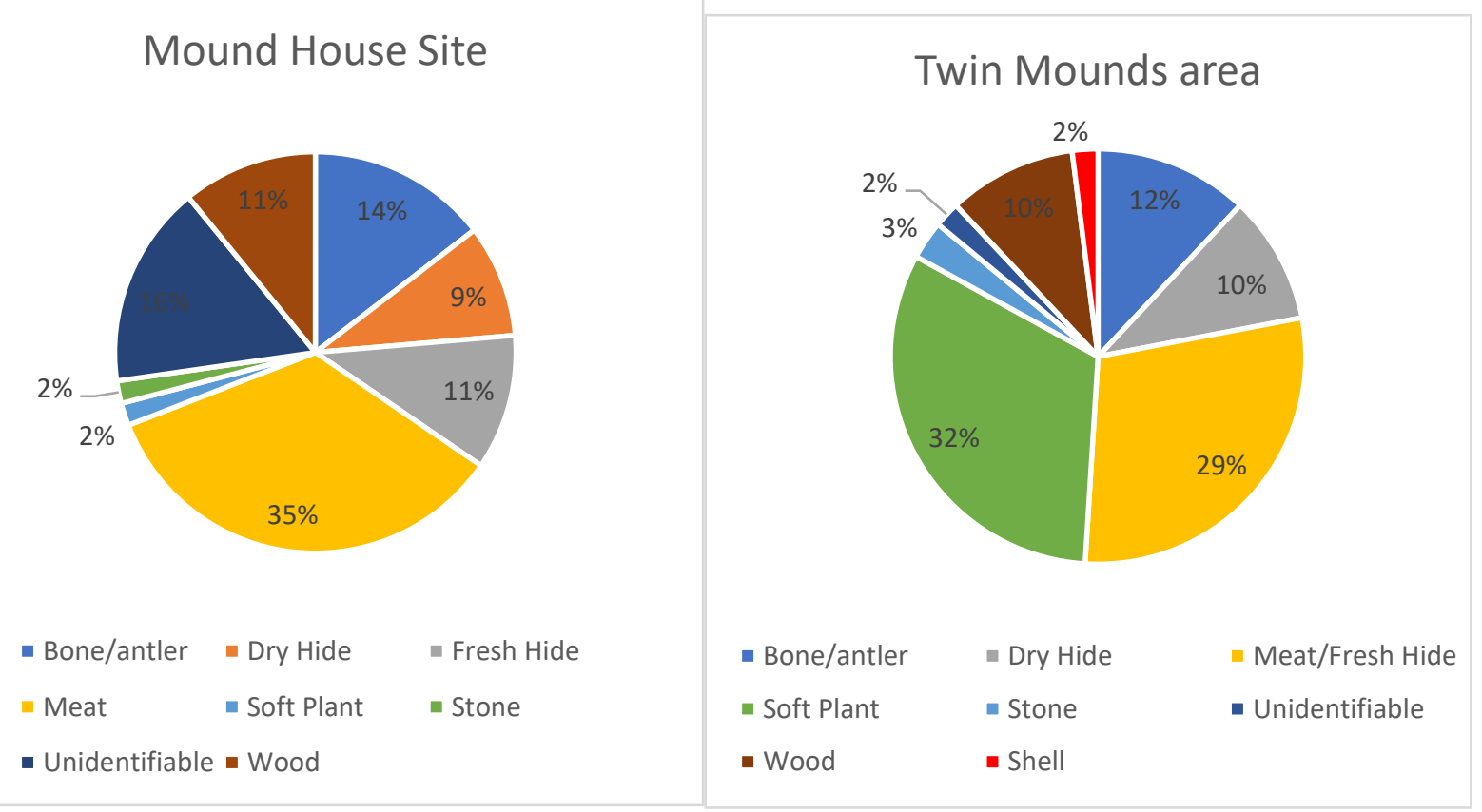

Figure 20. A comparison of the Mound House site and the Ft. Ancient site assemblage in the Twin Mounds area. 


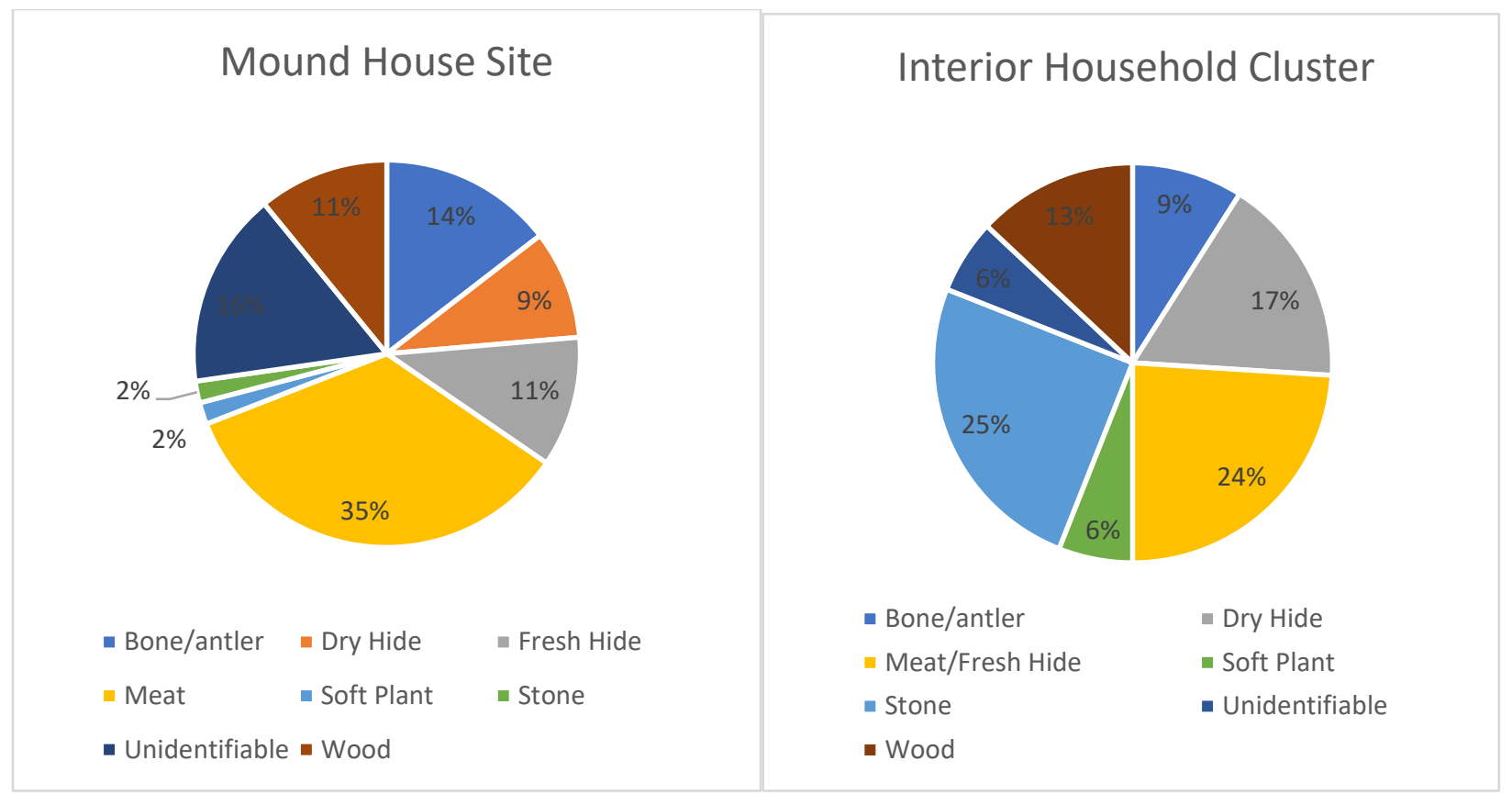

Figure 21. A comparison of the Mound House site and the Ft. Ancient site assemblage in the Interior Household Cluster.

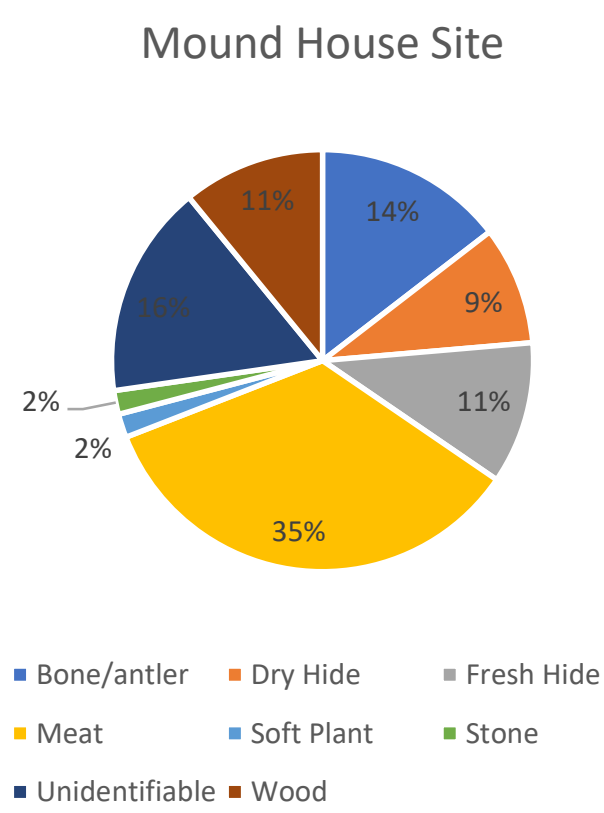

\section{Moorehead Circle}

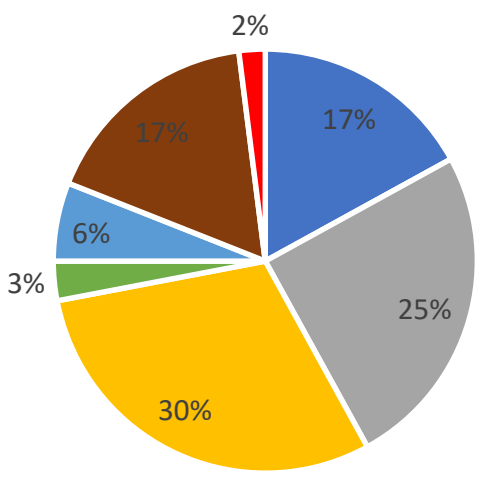

- Bone/antler

- Dry Hide

Meat/Fresh Hide

- Soft Plant

- Stone

- Wood

- Shell

Figure 22. A comparison of the Mound House site and the Ft. Ancient site assemblage in the Moorehead Circle. 


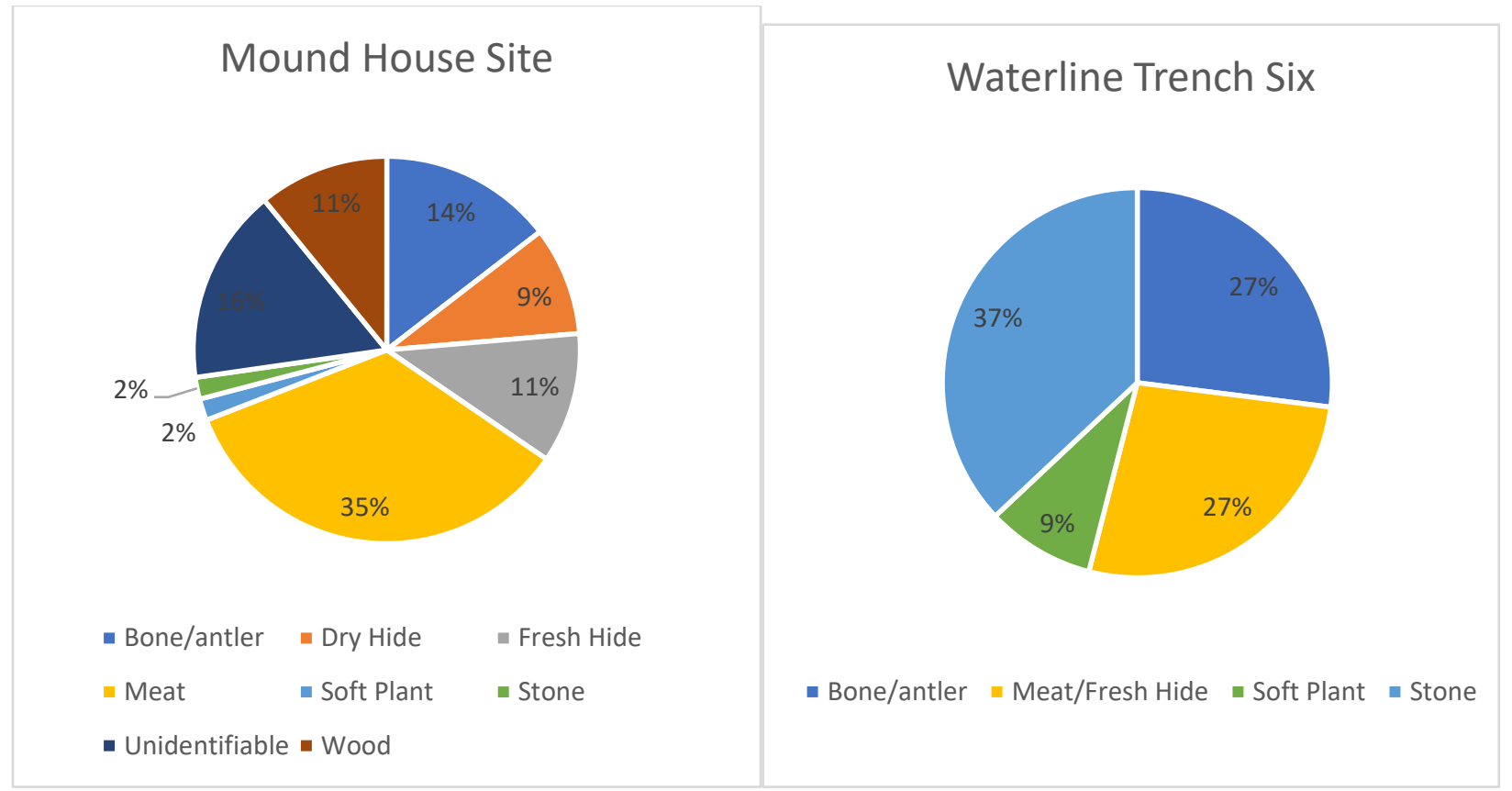

Figure 23. A comparison of the Mound House site and the Ft. Ancient site assemblage in Waterline Trench Six.

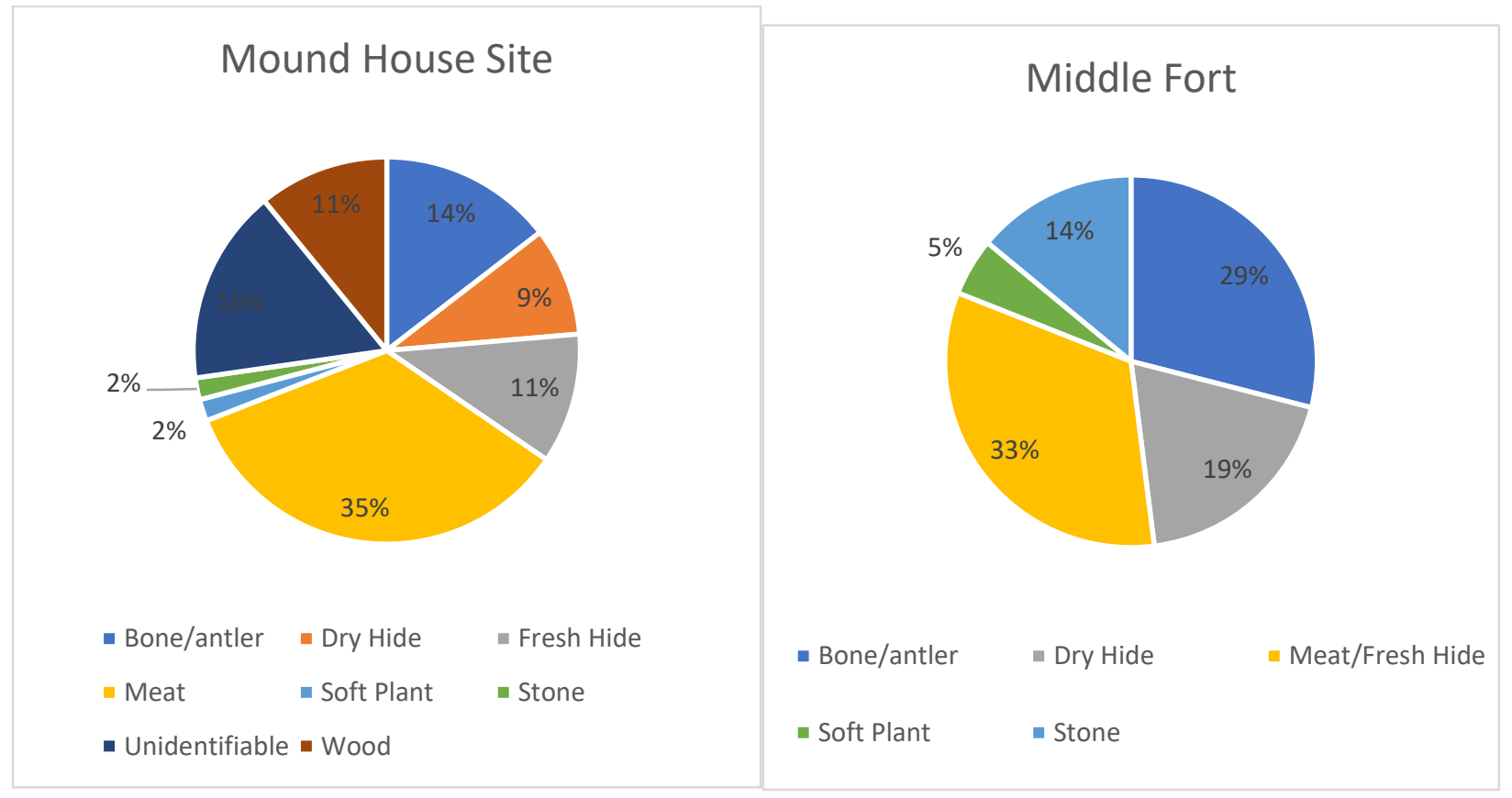

Figure 24. A comparison of the Mound House site and the Ft. Ancient site assemblage in the Middle Fort area. 
The other studies of Hopewell blade use-wear can't be compared to the Mound House site assemblage in the same way as the above studies. Odell (1994) use the low-power magnification technique, which leads him to categorize use-wear by hardness rather than specific material contacted. Kay and Mainfort (2014) note the different kinds of wear, but do not present frequencies in their data. Rather, they choose to focus of motion of use-wear and tool modification. Kimball (1992) also listed the types of materials represented, but did not present the numbers represented on the blade assemblage.

The broad pattern of use-wear at Mound House does not suggest that the blades at the site were a specialized tool, which matches the findings of similar studies (Kay and Mainfort 2014; Lemons and Church 1998; Miller 2015; Miller 2018b; Yerkes 1994). Comparing the Mound House assemblage to the Ft. Ancient Site and Stubbs Earthworks, there is much less evidence of craft production in terms of bone-working use-wear, stone use-wear, and the presence of shell use-wear. There is evidence that the production of Hopewell craft objects had a minor role at Mound House, with the bone-working and an instance of stone use-wear. Considering the relatively low number of Hopewell craft items recovered from the site during excavations and surface collections (Buikstra et al. 1998), this microwear data fits with what archaeologists currently know about the Mound House site. The microwear analysis of blades at Mound House shows a broad range of activities in which blades were used. Due to many of the activities $r$ being ambiguous in terms of craft vs. subsistence contexts (such as hide-working, bone sawing, wood working), it is safe to say that blades utilized by people at Mound House were also producing utilitarian objects. Likely, people who came to the site to participate in community activities did not cease their daily activities while they were at the site. The dominance of meat use-wear across the site, especially in the mound area, demonstrates the importance of feasting 
which relates to the community gathering taking place at the site. Meat use-wear is present on other blades from Middle Woodland sites, including habitations and earthworks. Considering that current models of activity at Mound House do not point to long term occupations, but to seasonal gatherings, the abundant meat use-wear at the site does not likely reflect butchery resulting accumulation over time by a few people, such as with the Murphy site.

The evidence for feasting via meat use-wear fits current models for what is known about Mound House and other floodplain mound groups in the Lower Illinois river valley. The Ohio earthworks sites that Mound House was compared to included the Ft. Ancient site and Stubbs earthworks. Stubbs had appreciably less meat related use-wear than Mound House, suggesting a lesser amount of feasting activity here. Ft. Ancient, in most of the different areas examined, had similar proportions of meat-processing use-wear in comparison to Mound House. Feasting is likely a common activity at other earthworks sites, especially those floodplain mound groups which are similar to Mound House but have yet to be examined. As Mound House and other floodplain mound groups are thought to have functioned as multi-community gathering places or “regional symbolic centers” (King, Buikstra, and Charles 2011; Ruby et al. 2005), feasting would have played an important role in this community space. Hall $(1973 ; 1997)$ argues that one of the reasons the interaction network of Hopewell was maintained was as a buffer strategy to deal with food shortages. Seeman (1979) takes this idea further by theorizing that feasting, associated with mortuary ritual at Ohio Hopewell sites, was a large part of Hopewell ceremonialism and served as a way to redistribute food to the community. His work looks at charnel houses associated with well-known Ohio sites such as Tremper, Seip, Mound City, and more. Seeman (1979) finds that meat seems to be associated with mortuary ritual at these sites. While the sites Seeman (1979) discusses are not directly comparable with Mound House, they 
serve to illustrate the importance of feasting by Middle Woodland communities in ceremonial contexts. However, it is hard to assert that meat use-wear is undoubtedly the result of feasting. Thornton (2014) who analyzed the faunal assemblage at Mound House showed that the faunal remain patterns at the site did not match well with what would be expected for feasting activity. Mound House faunal remains have a moderate amount of species diversity, which contrasts with the low species diversity that is expected in archaeological feasting contexts. White-tailed deer remains include all elements of the deer, as opposed to just choice cuts of meat (Thornton 2014). While feasts often only use certain cuts, by no means do all feasts only use certain types of cuts of meat. However, remains of exotic species, such as swan and bald eagle, also suggests a more special context to the food consumption here beyond everyday subsistence. Overall, Thornton (2014) does not rule out feasting at Mound House, but states that explicit evidence for it does not exist either. 


\section{CONCLUSION}

This work has presented an examination of Middle Woodland people at the Mound House site through the analytical tool of microwear analysis. Mound House is a unique, complex site which would have served as a ritual aggregation center for Middle Woodland people in the Lower Illinois River Valley. Prior to this analysis, most of what we knew about Mound House is investigations into the mound construction sequences. Looking for use-wear traces on onehundred Hopewell blades has revealed several things about the activities that occurred at Mound House. Overall, blades were utilized as fairly expedient tools for a number of purposes. The production of Hopewell craft items using blades seems to have been a minor activity at the site. The production of potentially utilitarian objects and subsistence tasks, like hide-working, woodworking, and some bone-working activities, are more common than the production of craft objects at Mound House. Ultimately, the activity most prominently evidenced by microwear analysis is meat processing, which likely is the result of communal feasting. A high focus on meat processing was present in both the habitation and mound areas but the pattern was especially pronounced in the mound area. As Mound House served as a place for a symbolic community to come together and reinforce their shared identity, feasting served as a way for them to participate in something together and bond. Feasting also would have served to redistribute food resources among the community members who were suffering food shortages. This would have further strengthened the ties of the symbolic community.

This study has served to not only interpret the activities and lifeways of people at Mound House, but also to compliment other studies of Hopewell blade microwear. Like other studies, the microwear analysis of blades at the Mound House site has demonstrated that these were not specialized tools but were used for any number of activities. To date this thesis is the only one to 
use high-power microscopy to examine Illinois Hopewell blades for use-wear. Future work is needed in this region in order to understand any broader patterns of use-wear across sites or lack thereof. Other studies, such as those in Ohio (Lemons and Church 1998; Miller 2015; 2018; Yerkes 1994), have shown that the distribution of different use-wear varies by context. Within Illinois, similar floodplain mound groups to Mound House, such as Kamp and Piesker, should be examined to see if there is a similar pattern shared across similar sites. Knowing whether or not sites that seem very similar had the same kinds of activities going on would be helpful in understanding Middle Woodland people in this region. Habitation sites, extractive camps, and bluff-top cemetery mound groups should also be examined in future use-wear studies. Since Middle Woodland people used these sites for different purposes, use-wear analyses would help paint a picture of Middle Woodland lifeways across a variety of site contexts. The spread of Hopewell artifacts and ideas to the various Middle Woodland peoples across the Eastern US is still something archaeologists are striving to understand better. Microwear analysis is a tool that can help reconstruct the activities of the Middle Woodland people who used them. Future studies similar to this thesis will aid in better understanding Middle Woodland period people and Hopewell on both local and regional scales. 


\section{REFERENCES CITED}

Abrams, Elliot M.

2009 Hopewell Archaeology: a View from the Northern Woodlands. Journal of Archaeological Research 17:169-204

Adams, JL

1993 Mechanisms of Wear on Ground Stone Surfaces. Pacific Coast Archaeology. Soc.

Q. 29: 60-73

Buikstra, Jane E., Douglas K. Charles, and Gordon F. M. Rakita

1995 Mound House 1994: Archaeology and the Great Flood of '93. A Revision of a

Final Report Submitted to the Illinois Historic Preservation Agency 1993 Flood

Disaster Relief Grant Project No. 17-93-FLOOD-40. Center for American

Archeology, Kampsville, Illinois.

1998 Staging Ritual: Hopewell Ceremonialism at the Mound House Site, Greene

County, Illinois. Kampsville Studies in Archeology and History, No. 1. Center for American Archaeology, Kampsville, Illinois.

Byers, A. Martin

2006 The Earthwork/Habitation Dichotomy in Recreating Hopewell. edited by Douglas

Charles and Jane Buikstra. pp. 62-73. University of Florida, Gainsville.

Caldwell, Joseph R.

1964 Interaction Spheres in Prehistory in Hopewellian Studies. Edited by Joseph R.

Caldwell and Robert L. Hall. pp. 133-156. Springfield, MO. 
Carr, Christopher

2005 Rethinking interregional Hopewellian “interaction”. In Gathering Hopewell. pp. 575-623. Springer, Boston, MA.

Charles, Douglas K., Julieann Van Nest, and Jane E. Buikstra

2004 From the Earth: Minerals and Meaning in the Hopewellian World. In Soils,

Stones, and Symbols: Cultural Perceptions of the Mineral World. Edited by Nicole

Boivin and Mary Ann Owoc. pp. 43-70. UCL Press London.

Dancey, William S.

2005 The Enigmatic Hopewell of the Eastern Woodlands. North American Archaeology. 108-137.

Deboer, Warren R.

2004 Little Bighorn on the Scioto: the Rocky Mountain Connection to Ohio Hopewell. American Antiquity 69(1): 85-107

Evans, Adrian A. and Randolph E. Donahue 2008 Laser Scanning Confocal Microscopy: A Potential Technique for the Study of Lithic Microwear. Journal of Archaeological Science 35(8): 2223-2230.

Fortier, Andrew C.

2000 The Emergence and Demise of the Middle Woodland Small-Tool Tradition in the American Bottom. Midcontinental Journal of Archaeology 25(2). Taylor \& Francis, Ltd. on behalf of the Midwest Archaeological Conference, Inc.

Gillreath-Brown, Andrew and Tanya M. Peres

2017 Identifying Turtle Shell Rattles in the Archaeological Record of the Southeastern United States. Ethnobiology Letters 8(1): 109-114. 
Greber, N'omi, Richard Davis, and Ann DuFresne

1981 The Micro Component of the Ohio Hopewell Lithic Technology: Bladelets.

Annals of the New York Academy of Sciences 376:489-528

Grubb, Thomas C.

1981 Why Hopewell Cores and Bladelets?. Ohio Archaeologist, 31(2): 18-20.

Hall, Robert L.

1973 An Interpretation of the Two-Climax Model of Illinois Prehistory. Paper presented at the $9^{\text {th }}$ International Congress of Anthropological and Ethnological Sciences, Chicago.

1977 An Anthropomorphic Perspective for Eastern United States Prehistory. American Antiquity 42(4): 499-518

1997 An Archaeology of the Soul: North American Indian Belief and Ritual. University of Illinois Press, Urbana and Chicago.

Helms, Mary

1988 Ulysses' Sail: An Ethnographic Odyssey or Power, Knowledge, and Geographic Distance.196. Princeton University Press, Austin.

Hill, Mark A., Mark F. Seeman, Kevin C. Nolan, Laure Dussubieux

2017 An Empirical Evaluation of Copper Procurement and Distribution: Elemental Analysis of Scioto Valley Hopewell Copper. Archaeological Anthropological Science. 10(5): 1193-1205. 
Hurcombe, Linda

1992 Use Wear Analysis and Obsidian: Theory, Experiments, and Results. Sheffield Archaeological Monographs 4. Sheffield: JR Collis Publications, University of Sheffield.

Kajiwara $\mathrm{H}$ and Akoshima K

1981 An Experimental Study of Microwear polish on shale artifacts. Kokogaku Zasshi 67: 1-36. (in Japanese).

Kamminga, Johan

1979 The Nature of Use-Polish and Abrasive Smoothing on Stone Tools. Lithic UseWear Analysis. 143-157.

Kay, Marvin and Robert C. Mainfort Jr.

2013 Functional Analysis of Prismatic Blades and Bladelets from Pinson Mounds, Tennessee. Journal of Archaeological Science 50: 63-83.

Kimball, Larry R.

1992 The Function of Hopewell Blades from the Southeast. Research Notes

1994 An Introduction to the Methodological and Substantive Contributions of Microwear Analysis. Lithic Technology 19(2): 81-82

Kimball, Larry R., John F. Kimball, Patricia E. Allen

1995 Microwear Polishes as Viewed Through the Atomic Force Microscope. Lithic Technology. 6-28

King, Jason L., Jane E. Buikstra and Douglas K. Charles

2011 Time and Archaeological Traditions in the Lower Illinois Valley. American Antiquity. 76(3): 500-528. Cambridge University Press. 
King, Jason L., Jane E. Buikstra, Taylor H. Thornton, Ang Demarco

2011 Middle and Late Woodland Occupations at the Mound House Site (11GE7), Greene County, Illinois. Presented at Midwest Archaeological Conference, October 13-15, 2011, La Crosse, Wisconsin. Center for American Archaeology, Kampsville, Illinois. Lemons, Reno and Flora Church.

1998 A Use Wear Analysis of Hopewell Bladelets from Paint Creek Lake Site \#5, Ross County, Ohio. North American Archaeologist 19(4): 269-277

Lynott, Mark J.

2015 Hopewell Ceremonial Landscapes of Ohio. American Landscapes vol. 1. Oxbow Books.

Miller, Logan.

2015 Ritual Economy and Craft Production in Small-scale Societies: Evidence from Microwear Analysis of Hopewell Bladelets. Faculty Publications-Sociology and Anthropology. 3.

2018a Hopewell Bladelets: a Bayesian Radiocarbon Analysis. American Antiquity 83(2): 224-243

2018b Microwear Analysis of Hopewell Bladelets from Two Sites Associated with the Stubbs Earthworks, Southwest Ohio. Midcontinental Journal of Archaeology. 43(3): 281-297. 
Morrow, Carol A.

1987 Blades and Cobden Chert: A Technological Argument for Their Role as Markers of Regional Identification During the Hopewell Period in Illinois. in The Organization of Core Technology edited by Jay K. Johnson and Carol A. Morrow, pp. 119-149. Westview Press, Boulder, Colorado.

Mueller, Natalie G.

2013 Mound Centers and Seed Security: A Comparative Analysis of Botantical Assemblages from Middle Woodland Sites in the Lower Illinois Valley. Department of Anthropology, Washington University of St. Louis. St. Louis, MO. Springer. pp. 1-64.

Price-Beggerly, Patricia

1976 Edge Damage on Experimentally used scrapers of Hawaiian Basalt. Lithic Technology 5(3): 22-24.

Reid, Kenneth C.

1975 Prehistoric trade in the lower Missouri River Valley: an analysis of middle woodland bladelets. PhD dissertation, University of Kansas, Anthropology. Lawrence, Kansas.

Rots, Veerle

2005 Wear Traces and the Interpretation of Stone Tools. Journal of Field Archaeology 30(1): $61-73$

Rots, Veerle., L. Pirnay, Ph. Pirson, and O. Baudoux 2006 Blind Tests Shed Light on Possibilities and Limitations for Identifying Stone Tool Prehension and Hafting. Journal of Archaeological Science 33: 935-952 
Ruby, Bret J., Christopher Carr, and Douglas K. Charles

2005 Community Organization in the Scioto, Mann, Havana Hopewellian Regions: A Comparative Perspective. In Gathering Hopewell. Edited by Christopher Carr and Troy D. Case. Springer, Boston, Massachusetts. 119-176

Sarich, Steven

2010 Deconstructing the Hopewell Interaction Sphere. Nebraska Anthropologist 59.

Department of Anthropology. University of Nebraska-Lincoln.

Scarry, Margaret C. and Richard A. Yarnell

2011 Native American Domestication and Husbandry of Plants in Eastern North America. In The Subsistence Economies of Indigenous North American Societies.

Edited by Bruce D. Smith. pp. 483-501. Smithsonian Institution Scholarly Press. Seeman, Mark F.

1979 Feasting with the Dead: Ohio Hopewell Charnel House Ritual as a Context for Redistribution. In Hopewell Archaeology The Chillicothe Conference. Edited by David S. Brose and N'omi Greber. pp. 39-46. Kent State University Press.

1995 When Words Are Not Enough: Hopewell Interregionalism and the Use of Material Symbols at the GE Mound. In Native American Interactions: Multiscalar Analyses and Interpretations in the Eastern Woodlands. Edited by Mark F. Seeman, Michael S. Nassaney, and Kenneth E. Sassaman. pp. 122-143.

Semenov, Sergei A.

1964 Prehistoric Technology. Translated by M. W. Thompson, Barnes and Noble, New York. 
Smith, Bruce D.

1992 Hopewellian Farmers of Eastern North America. In Rivers of Change: Essays on Early Agriculture in Eastern North America. Bruce D. Smith with contributions by C. Wesley Cowan and Michael P. Hoffman. pp. 201-248. Smithsonian Institution Press, Washington, DC.

Stemp James W., Adam S. Watson, and Adrian A. Evans

2016 Surface Analysis of Bone and Stone Tools. Surface Topology, Metrology and Properties. 4(1): 013001.

Struever, Stuart

1965 Middle Woodland Culture History in the Great Lakes Riverine Area. American Antiquity 31(2): 211-223. 2Part 1. Cambridge University Press.

Struever, Stuart and Gail L. Houart

1972 An Analysis of the Hopewell Interaction Sphere. Social Exchange and Interaction 46:47-79.

Styles, Bonnie W.

2011 Animal use by Holocene aboriginal societies of the Northeast. In Subsistence Economies of Indigenous North American Societies: 483-501.

Sussman, Carole

1985 Microwear on Quartz: Fact or Fiction? World Archaeology 17(1): 101-111. 
Thornton, Taylor H.

2014 Extra-Moundbuilding Activities in the Floodplain: a Zooarchaeological Perspective from the Mound House Site (11GE7). Bachelor's Thesis. College of Liberal Arts and Sciences. University of Illinois Urbana-Champaign. Urbana Champaign, Illinois.

Tomak, Curtis H.

1994 The Mount Vernon Site: A Remarkable Hopewell Mound in Posey County, Indiana. Archaeology of Eastern North America 22: 1-46.

Van Gijn, Anne Lou

1990 The Experiments. In The Wear and Tear of Flint: Principles of Microwear Analysis Applied to Dutch Neolithic Assemblages. Analecta Praehistorica Leidensia 22, University of Leiden.

Von Gernet, Alexander

2000 North American Indigenous Nicotiana Use and Tobacco Shamanism. In Tobacco Use by Native North Americans: Sacred Smoke and Silent Killer. Edited by Joseph C. Winter. pp. 59-83. University of Oklahoma Press: Norman.

Yerkes, Richard W.

1994 A Consideration of the Function of Ohio Hopewell Bladelets. Lithic Technology 19(2):109-127.

2009 Microwear Analysis of a Sample of 100 Chipped Stone Artifacts from the 19711977 Ohio Historical Society Excavations at the Seip Earthworks. Midcontinental Journal of Archaeology 34(1):109-121. 
Yerkes, Richard W. and P. Nick Kardulias

1993 Recent Developments in the Analysis of Lithic Artifacts. Journal of Archaeological Research 1(2):89-119. 